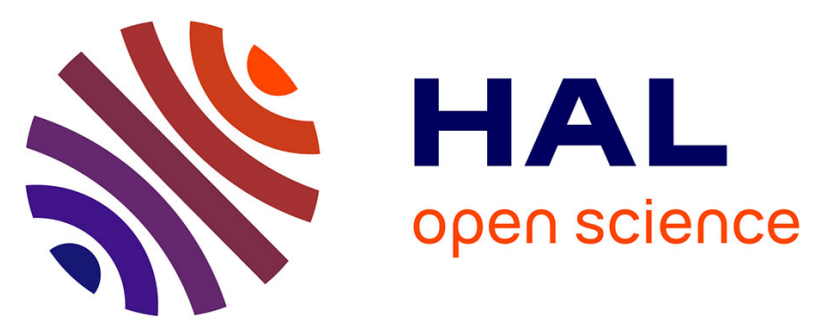

\title{
Alteration Analysis of Bone Marrow Mesenchymal Stromal Cells from De Novo Acute Myeloid Leukemia Patients at Diagnosis
}

Laura Desbourdes, Joaquim Javary, Thomas Charbonnier, Nicole Ishac, Jerome Bourgeais, Aurore Iltis, Jean-Claude Chomel, Ali Turhan, Fabien Guilloton, Karin Tarte, et al.

\section{To cite this version:}

Laura Desbourdes, Joaquim Javary, Thomas Charbonnier, Nicole Ishac, Jerome Bourgeais, et al.. Alteration Analysis of Bone Marrow Mesenchymal Stromal Cells from De Novo Acute Myeloid Leukemia Patients at Diagnosis. Stem Cells and Development, 2017, 26 (10), pp.709-722. 10.1089/scd.2016.0295 . hal-01560454

HAL Id: hal-01560454

https://hal-univ-rennes1.archives-ouvertes.fr/hal-01560454

Submitted on 11 Jul 2017

HAL is a multi-disciplinary open access archive for the deposit and dissemination of scientific research documents, whether they are published or not. The documents may come from teaching and research institutions in France or abroad, or from public or private research centers.
L'archive ouverte pluridisciplinaire HAL, est destinée au dépôt et à la diffusion de documents scientifiques de niveau recherche, publiés ou non, émanant des établissements d'enseignement et de recherche français ou étrangers, des laboratoires publics ou privés. 


\title{
Alteration Analysis of Bone Marrow Mesenchymal Stromal Cells from De Novo Acute Myeloid Leukemia Patients at Diagnosis
}

\author{
Laura Desbourdes,, Joaquim Javary, Thomas Charbonnier, Nicole Ishac,, \\ Jerome Bourgeais, ${ }^{1}$ Aurore Iltis, 2,3 Jean-Claude Chomel, ${ }^{4,5}$ Ali Turhan,, Fabien Guilloton, \\ Karin Tarte, ${ }^{8-10}$ Marie-Veronique Demattei, ${ }^{11}$ Elfi Ducrocq, ${ }^{1}$ Florence Rouleux-Bonnin, \\ Emmanuel Gyan, ${ }^{1,3}$ Olivier Hérault, ${ }^{1,2,10}$ and Jorge Domenech ${ }^{1,2,10}$
}

Bone marrow (BM)-derived mesenchymal stromal cells (MSCs) frequently display alterations in several hematologic disorders, such as acute lymphoid leukemia, acute myeloid leukemia (AML), and myelodysplastic syndromes. In acute leukemias, it is not clear whether MSC alterations contribute to the development of the malignant clone or whether they are simply the effect of tumor expansion on the microenvironment. We extensively investigated the characteristics of MSCs isolated from the BM of patients with de novo AML at diagnosis (L-MSCs) in terms of phenotype (gene and protein expression, apoptosis and senescence levels, DNA double-strand break formation) and functions (proliferation and clonogenic potentials, normal and leukemic hematopoiesis-supporting activity). We found that L-MSCs show reduced proliferation capacity and increased apoptosis levels compared with MSCs from healthy controls. Longer population doubling time in L-MSCs was not related to the AML characteristics at diagnosis (French-American-British type, cytogenetics, or tumor burden), but was related to patient age and independently associated with poorer patient outcome, as was cytogenetic prognostic feature. Analyzing, among others, the expression of 93 genes, we found that proliferative deficiency of L-MSCs was associated with a perivascular feature at the expense of the osteo-chondroblastic lineage with lower expression of several niche factors, such as KITLG, THPO, and ANGPTI genes, the cell adhesion molecule VCAM1, and the developmental/ embryonic genes, BMII and DICERI. L-MSC proliferative capacity was correlated positively with CXCL12, $T H P O$, and ANGPTI expression and negatively with JAGl expression. Anyway, these changes did not affect their in vitro capacity to support normal hematopoiesis and to modify leukemic cell behavior (protection from apoptosis and quiescence induction). Our findings indicate that BM-derived MSCs from patients with newly diagnosed AML display phenotypic and functional alterations such as proliferative deficiency that could be attributed to tumor progression, but does not seem to play a special role in the leukemic process.

Keywords: hematopoiesis, microenvironment, mesenchymal stromal cells, niche, acute myeloid leukemia

\section{Introduction}

$\mathrm{D}$ YSFUNCTIONS OF THE hematopoietic system can lead to the emergence of malignancies such as acute myeloid leukemias (AMLs), which involve the hematopoietic stem cell (HSC) compartment. These disorders originating from bone marrow $(\mathrm{BM})$ are characterized by clonal proliferation of cells having lost more or less their maturation capacities associated with a dramatic suppression of normal polyclonal hematopoiesis [1]. The mechanisms underlying this suppression are not yet completely elucidated. Indeed, it can be observed also in the case of limited leukemic cell infiltration and therefore it cannot be explained only by BM expansion of tumor cells. The heterogeneity of the AML cell population is now well

${ }^{1}$ CNRS UMR 7292, LNOx Team, François Rabelais University, Tours, France.

Departments of ${ }^{2}$ Biological Hematology and ${ }^{3}$ Hematology and Cell Therapy, University Hospital of Tours, Tours, France.

${ }^{4}$ INSERM U935, University of Poitiers, Poitiers, France.

${ }^{5}$ Department of Biological Oncology, University Hospital of Poitiers, Poitiers, France.

${ }^{6}$ INSERM U935, University of Paris-Sud 11, Paris, France.

${ }^{7}$ Department of Hematology, University Hospitals of Paris-Sud, Le Kremlin Bicêtre, France.

${ }^{8}$ INSERM U917, University of Rennes 1, Rennes, France.

${ }^{9}$ Department of Immunology, Cellular Therapy and Hematopoiesis, University Hospital of Rennes, Rennes, France.

${ }^{10}$ CNRS GDR 3697, MicroNiT National Network, Tours, France.

${ }^{11}$ CNRS UMR 7292, Telomeres and Genome Stability Team, François Rabelais University, Tours, France. 
established and includes a rare subpopulation named leukemic stem cells (LSCs) that are regulated by the BM stromal compartment [2-4]. LSCs can maintain and promote tumor cell propagation and favor resistance to treatment [5].

Mesenchymal stromal cells (MSCs) are the main cellular component of the hematopoietic niche [6-8] in the BM, a specialized microenvironment site that controls self-renewal and quiescence of HSCs. MSCs are multipotent cells that give rise to vascular smooth muscle cells, adipocytes, osteoblasts of the BM, and also chondroblasts. Alterations of the BM stromal cell compartment have been shown in de novo AML, including a reduction in the number of fibroblasts and adipocytes and a decreased growth capacity [9-14]. However, it is not yet evident if MSC long-term hematopoietic-supporting activity in AML at diagnosis is intrinsically impaired [12] or not [10]. Otherwise, several recent reports have highlighted the abnormal MSC function in chronic preleukemic diseases such as myelodysplastic syndromes (MDSs) [15-17] in contrast to chronic myelogenous leukemia (CML) [18,19].

In primary $A M L$, it remains to be clarified whether the observed microenvironmental alterations contribute to the development of the malignant clone or are simply the consequence of cancer cell proliferation at the onset of the disease. Some reports have shown that leukemic cells alter the hematopoietic function of the BM microenvironment by disrupting the hematopoietic niches [20] and by inducing sympathetic neuropathy that increases BM leukemic infiltration [21]. In addition, the microenvironment contribution to leukemia progression has been suggested by the occurrence of hematopoietic malignancies derived from donor cells in recipients of allogeneic HSC transplants [22,23] and was demonstrated in animal models [24-26].

The present study investigated the relationship between the phenotype (extensively analyzed) and function of MSCs isolated from the BM of patients with newly diagnosed de novo AML (L-MSCs). As in previous reports, we found that LMSCs often display a proliferative deficiency. In this study, we show that this abnormality, correlated with the patient's age, is not related to AML characteristics at diagnosis [FrenchAmerican-British (FAB) type, cytogenetics, or tumor burden] and is independently associated with poorer patient outcome. Analyzing, among others, the expression of 93 genes, we found that proliferative deficiency of L-MSCs was associated with a perivascular feature at the expense of the osteochondroblastic lineage with lower expression of several niche factors, such as KITLG, THPO, and ANGPT1, the cell adhesion molecule $V C A M 1$, and the developmental/embryonic genes, BMII and DICERI. L-MSC proliferative capacity correlated positively with $C X C L 12, T H P O$, and ANGPT1 expression and negatively with $J A G 1$ expression. Nevertheless, these changes, probably induced by tumor expansion, did not affect the in vitro capacity of MSCs to support normal hematopoiesis and to modify the leukemic cell biology (protection from apoptosis and quiescence induction).

\section{Materials and Methods}

\section{Patients and normal controls}

All patients included in this study (12 males and 7 females) had de novo AML followed at the Department of
Clinical Hematology, University Hospital, Tours, France, and gave their informed consent for cell banking according to the Declaration of Helsinki, and the study was approved by the French Ministry of Higher Education and Research (authorization number No. DC-2008-308). BM samples were collected at diagnosis for MSCs and contained $87 \%$ of blast cells (median value), while peripheral blood (PB) leukocyte count was in median $57 \mathrm{~g} / \mathrm{L}$. Patients had a median age of 48 years at the time of BM aspiration. According to the FAB classification, AMLs were classified as AMLM0/1 ( $n=10$ patients), AML-M3 $(n=3)$, and AML-M4/5 $(n=6)$. The patients' clinical data are reported in Supplementary Table S1 (Supplementary Data are available online at www.liebertpub.com/scd). In parallel, BM MSCs from normal controls without any hematological disorder (seven males and three females; median age: 59.5 years) were isolated. They were informed and consenting patients underwent orthopedic surgery (Orthopedic Surgery Department, Trousseau Hospital, Tours, France), or for brain-dead organ donors, just before organ harvesting (protocol approved by the French Biomedicine Agency, no. PFS10-007), the family provided the written informed consent.

\section{BM-derived MSC expansion and clonogenic capacity}

BM cells obtained by iliac crest or sternal aspiration were centrifuged and propagated in expansion medium.

Proliferation capacity. To measure MSC proliferation capacity, the population doubling time (PDT) was estimated at each passage and by flow cytometry using the carboxyfluorescein succinimidyl ester (CFSE).

Colony-forming unit-fibroblast assay. MSC clonogenic capacity was assessed by seeding $10-40 / \mathrm{cm}^{2}$ adherent cells in T-25 flasks. At day 10, cell clusters containing more than 50 cells were scored as colony-forming unit-fibroblast (CFU-F) colonies using an inverted microscope. Details are provided in the Supplementary Methods section in Supplementary Data.

\section{BM-derived MSC differentiation potential}

Multipotency of adherent MSCs was evaluated by inducing differentiation toward the adipogenic, osteogenic, and chondrogenic lineages. Detailed information is available in the Supplementary Methods section in Supplementary Data.

\section{MSC cycle analysis}

The percentage of detached MSCs in the G0, G1, or S/G2/ $M$ phase of the cell cycle was determined by flow cytometry after staining with 7-AAD and an anti-human KI67-Alexa Fluor 488-conjugated antibody, as previously described [27]. Additionally, expression of the cell cycle proteins, cyclin D1, p21, p27, and p53, in MSCs was investigated by western blotting. Details are provided in the Supplementary Methods section in Supplementary Data.

\section{MSC damage evaluation}

MSC apoptosis. Cell apoptosis rate was assessed by flow cytometry using the Annexin V-fluorescein isothiocyanate (FITC)/7-AAD Kit (Beckman Coulter) [28]. Late apoptosis was assessed in ethanol-permeabilized cells after 7-AAD staining to detect hypoploid nuclei (sub-G1 peak). 
Cell senescence. Senescence rates were assessed on adherent layers of MSCs at $70 \%$ confluence, using the Senescence Cells Histochemical Staining Kit (Sigma Aldrich).

MSC telomere length. DNA from MSCs was extracted with the Genomic DNA from Tissue kit (Macherey-Nagel Dueren). MSC telomere length was measured by Southern blot analysis of terminal restriction fragments as previously described [29].

Reactive oxygen species production. The amount of intracellular reactive oxygen species (ROS) was evaluated in trypsin/ethylenediaminetetraacetic acid (EDTA)-harvested MSCs by CM-H2DCFDA staining (Molecular Probes).

DNA double-strand break formation. The presence of DNA double-strand breaks (DSBs) was assessed in detached MSCs by staining with an FITC-conjugated antibody against phospho-histone H2AX (Ser139) ( $\gamma \mathrm{H} 2 \mathrm{AX}$ ) (clone JBW301, IgG1; EMD Millipore) after ethanol permeabilization. Details are provided in the Supplementary Methods section in Supplementary Data.

\section{MSC gene and protein expression related to niche function}

Reverse transcriptase-quantitative polymerase chain reaction analysis. We evaluated 93 genes (Supplementary Table S2) by TaqMan reverse transcriptase-quantitative polymerase chain reaction analysis (RT-qPCR).

Cytokine concentration in MSC supernatants. Cytokine levels were measured in supernatants of subconfluent MSCs at P2 by enzyme-linked immunosorbent assay (ELISA) using the Quantikine Human Immunoassays (R\&D Systems) for stromal cell-derived factor-1 alpha (SDF-1 $\alpha$ ), angiopoietin-1 (ANG-1), thrombopoietin (TPO), and stem cell factor (SCF), according to the manufacturer's recommendations.

Immunophenotype analysis. Membrane antigen expression was assessed by flow cytometry after direct (for CD45, CD14, CD34, CD309, CD73, CD90, CD105, CD49e, and CD146) or indirect (for CD106) staining of trypsin/EDTAdetached subconfluent MSCs at P2.

Immunofluorescence. The MSC expression of fibronectin, alpha smooth muscle actin (ASMA), and nestin was observed by immunofluorescence staining. Details are provided in the Supplementary Methods section in Supplementary Data.

\section{MSC hematopoietic-supporting activity assessed by Dexter-type long-term cultures}

Confluent MSCs cultured in T-25 flasks were irradiated and recharged with normal peripheral $\mathrm{CD} 34^{\text {pos }}$ cells in hydrocortisone-supplemented Myelocult ${ }^{\circledR}$ medium (H5100; StemCell Technologies) as described in the Supplementary Methods section in Supplementary Data. Hematopoietic progenitor cell (HPC) production was assessed weekly for 5 weeks.

\section{MSC leukemic cell supporting activity}

MSC influence on leukemic cell behavior was evaluated by coculturing MSCs from patients with AML-M0/1 (LMSC) or from controls (N-MSC) with KG1a cells for 3 days ( $n=6 /$ each group) or with primary blast cells (AML-M0/1) in heterologous or autologous settings for 2 days $(n=4$ for each group and each setting). Controls were KG1a cells $(n=3)$ and primary blast cells $(n=4)$ grown without MSCs.
Apoptosis rate [28], cell cycle distribution [27], and DNA DSBs in leukemic cells (CD45 ${ }^{\text {pos }}$ cell fraction) grown with or without MSCs were assessed by flow cytometry. Detailed information is available in the Supplementary Methods section in Supplementary Data.

\section{Statistical analyses}

N-MSCs and L-MSCs were compared using the nonparametric Mann-Whitney test in all experiments, except for cocultures of MSCs with leukemic cells where paired values were analyzed with the nonparametric Wilcoxon test. Correlations between quantitative values were evaluated by the Spearman rank test. Multivariate analysis was performed using the multiple stepwise regression test. Differences were considered significant when $P<0.05$.

\section{Results}

Adherent cells from BM of patients with AML exhibit characteristics of multipotent MSCS

To characterize the adherent BM cells isolated from patients with newly diagnosed AML and from controls, the expression of hematopoietic (CD14, CD34, and CD45) and endothelial (CD31 and CD309) markers was assessed at P2 and found to range between $<1 \%$ and $5 \%$. CD $45^{\text {neg }}$ cells from patients and controls expressed classical MSC markers (CD73, CD90, and CD105) (Fig. 1A) and could differentiate into adipogenic, osteogenic, and chondrogenic lineages (Fig. 1B). These results indicate that BM-derived adherent cells from both patients with AML (L-MSCs) and normal controls (N-MSCs) meet all the criteria to be considered MSCs [30] and show no obvious different characteristics.

\section{The proliferation capacity of MSCs isolated from patients with $A M L$ is decreased and is independently related to patient outcome}

MSC proliferation capacity was assessed by calculating the PDT, which was significantly longer in L-MSC than in N-MSC samples $(P<0.01$; Fig. $2 \mathrm{~A})$ with wide interindividual variation. Conversely, the clonogenic potential, evaluated with the CFU-F assay in MSC samples at P2, tended to be lower in L-MSC than in N-MSC samples $(P=0.16$; Fig. 2B), while an inverse correlation was found between CFU-F and PDT values $(\rho=0.79, P<0.001)$. Interestingly, L-MSCs isolated at diagnosis from patients who experienced treatment failure or early relapse (Supplementary Table S1) had significantly higher PDT values at P2 than L-MSCs from patients remaining in complete remission (Fig. 2C; $P<0.01$ ). No significant correlation was found between PDT and sex, FAB type, PB leukoblast count, BM leukoblast percentage, and cytogenetic prognostic feature at diagnosis. However, PDT correlated with patient age, as expected $(\rho=0.57 ; P<0.05)$. The lower LMSC proliferation capacity was confirmed by the decreased difference between the mean fluorescent intensity values of CFSE staining at 24 and $96 \mathrm{~h}$ in L-MSC cultures compared with controls $(P<0.05$; Fig. 2D). However, no difference in the cell cycle distribution between N-MSC and L-MSC samples was detected by flow cytometry analysis after 7AAD and KI-67 staining (Supplementary Fig. S1A). 


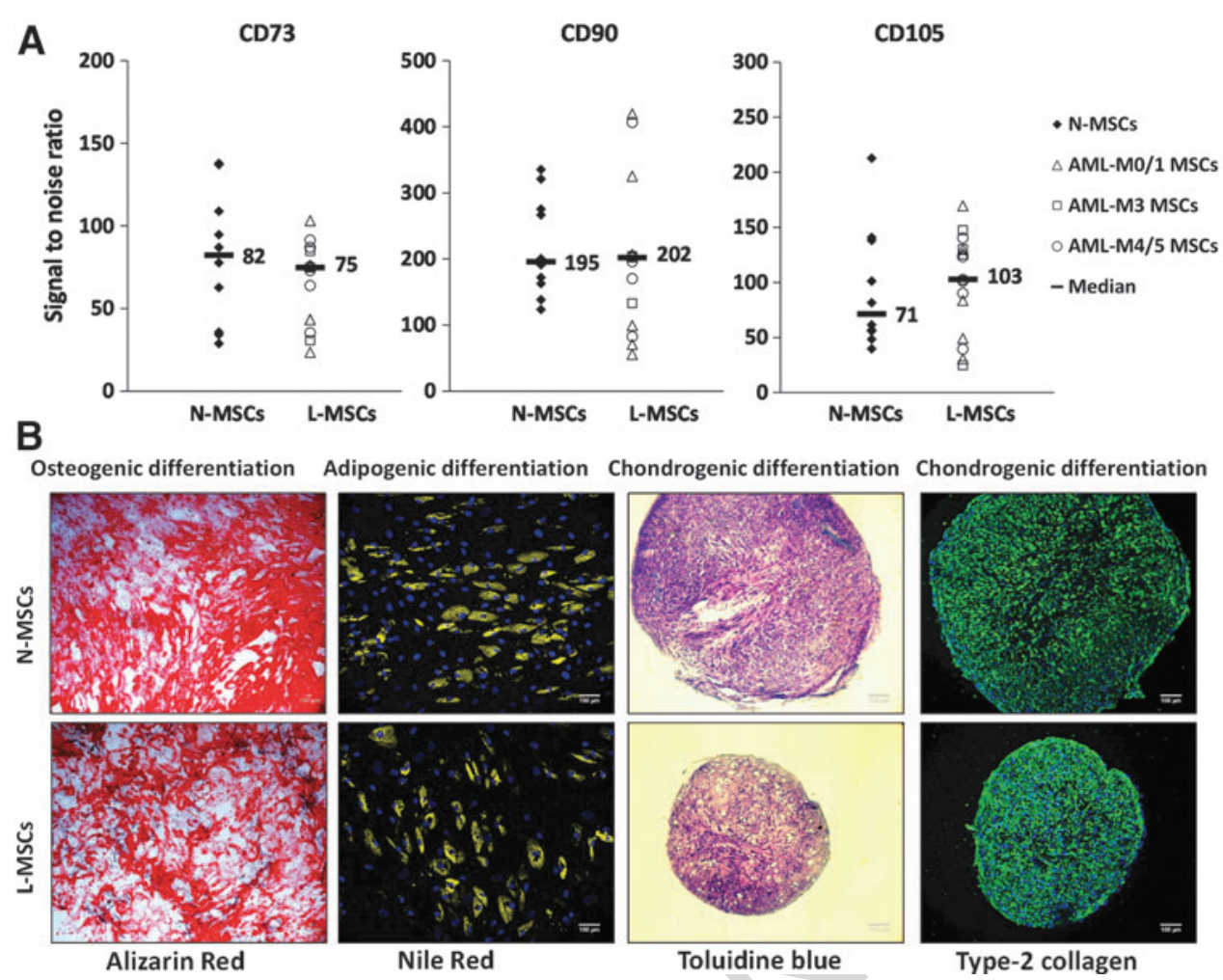

FIG. 1. Adherent cells from bone marrow of AML patients and normal controls display typical mesenchymal characteristics. (A) Expression of classical MSC markers measured by flow cytometry in adherent CD45 ${ }^{\text {neg }}$ cells from patients with AML (L-MSCs; $n=15$ ) and controls (N-MSCs; $n=10)$. Values are the signal-to-noise ratios determined by calculating the ratio of the median fluorescent intensities for specific antibody and isotype-matched control antibody. Black diamonds, individual N-MSC samples; triangles, individual L-MSC samples from patients with AML-M0/1; squares, individual LMSC samples from patients with AML-M3; circles, individual L-MSC samples from patients with AML-M4/5. Horizontal bars represent the medians. (B) L-MSCs $(n=14)$ have the same differentiation potential as N-MSCs $(n=10)$. Representative microphotographs of osteogenic, adipogenic, and chondrogenic differentiation of MSCs from one control (N-MSCs) and one patient with AML (L-MSCs). For osteogenic and adipogenic differentiation, confluent cells were exposed to a specific induction medium for 2 weeks. The presence of calcium deposits in osteocytes was revealed by Alizarin Red staining. Cellular neutral lipid vacuoles were stained with Nile Red (yellow). Chondrogenic differentiation was performed on cell pellets. After 3-week induction, the presence of glycosaminoglycans was revealed by toluidine blue staining and of type II collagen by immunofluorescence (green). Cell nuclei were stained with DAPI (blue). Scale bars $=100 \mu \mathrm{m}$. MSC, mesenchymal stromal cell; AML, acute myeloid leukemia; DAPI, 4',6-diamidino-2-phenylindole.

Accordingly, cell cycle regulatory proteins (cyclin D1, p21, p27, and p53) were expressed at comparable levels in LMSC and N-MSC cultures (Supplementary Fig. S1B, C).

Flow cytometry analysis after Annexin V/7-AAD staining revealed higher rates of early apoptotic cells $\left(7-\mathrm{AAD}^{\text {neg }} /\right.$ Annexin $\left.\mathrm{V}^{\text {pos }}\right)(P<0.05$; Fig. 3A) and also necrotic cells $(7-$ $\mathrm{AAD}^{\text {pos }} /$ Annexin $\left.\mathrm{V}^{\text {pos }}\right)(P<0.05$; data not shown) in L-MSC than in N-MSC cultures at P2. Likewise, when only late apoptosis was investigated, after 7-AAD staining, L-MSCs showed an increase in the percentage of hypoploid cells (subG1 phase) $(P<0.05$; Fig. 3B). Similar results were obtained when the death rate was measured with trypan blue exclusion staining $(P<0.05)$. However, increased levels of DNA DSBs, cell senescence, telomere length changes, and intracellular ROS levels could not be detected in L-MSCs when evaluated at the end of the second passage (Supplementary Fig. S2AD). It should be noted that senescence values in L-MSCs were particularly dispersed (Supplementary Fig. S2B).

To investigate whether L-MSC characteristics (PDT, clonogenic potential, senescence levels) might indepen- dently influence patient outcome (complete remission or disease progression), a multivariate stepwise regression analysis was carried out by integrating these variables with patient and disease characteristics (sex, age, PB leukoblast count, BM leukoblast percentage, FAB type, and cytogenetic prognostic feature at diagnosis). The only two independent prognostic factors found for patient outcome $(P<0.01)$ were cytogenetic prognostic value $(F=6.11)$ and especially PDT $(F=13.63)$.

\section{The expression of niche factors is downregulated in MSCs from AML patients}

To further characterize L-MSCs, the expression of 95 genes (including the control genes B2M and EIF2B1; Supplementary Table S2) was evaluated in L-MSCs and NMSCs by RT-qPCR. Although 11 genes could not be amplified (CCL19, COL2A1, CXCL9, GPX2, GPX5, IHH, LPL, PROM1, SHH, TERT, and WNT3A), the transcriptional profile of the other genes, including 22 niche-related genes, 

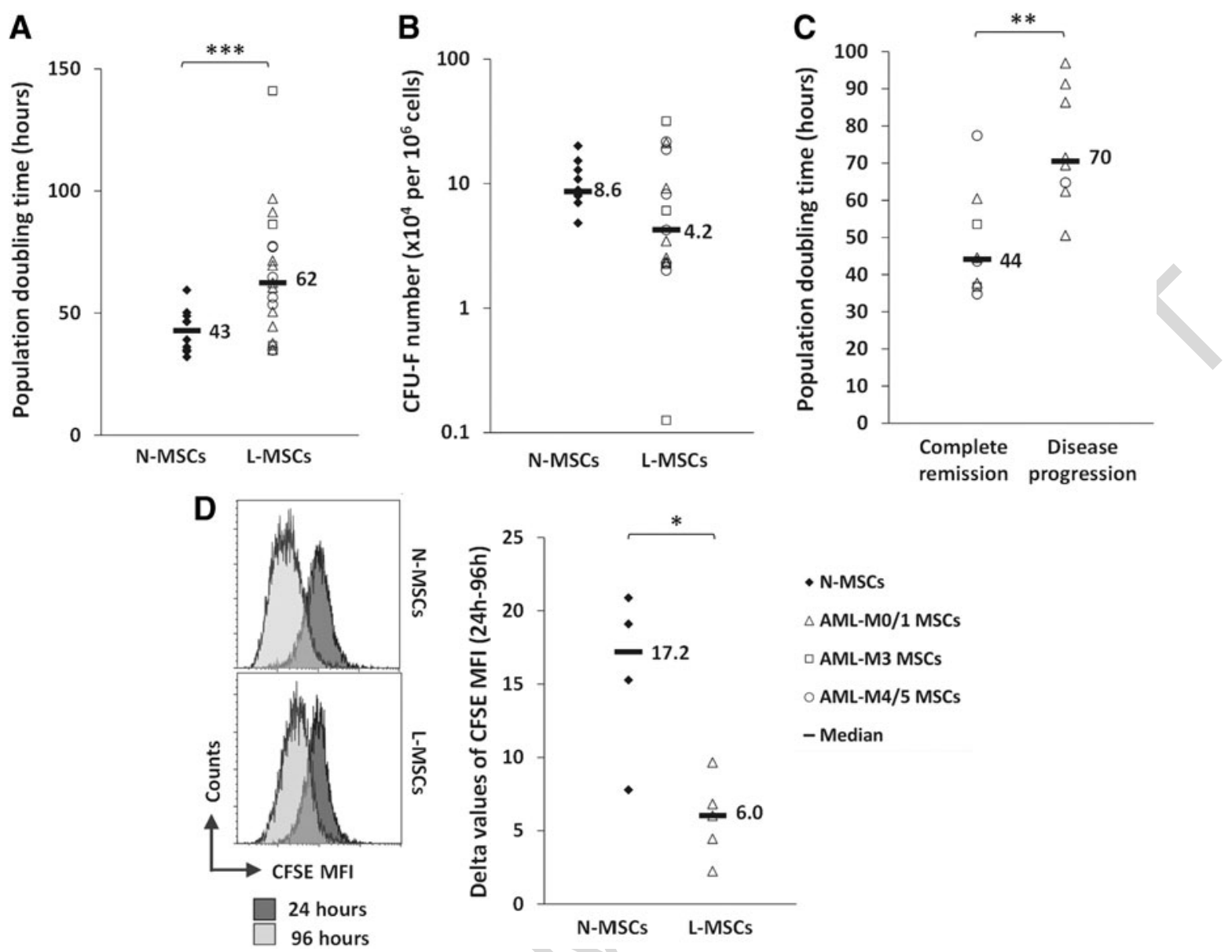

FIG. 2. MSCs from AML patients (L-MSCs) have lower proliferative potential than MSCs from normal individuals (NMSCs). (A) Cell proliferation capacity determined by PDT of L-MSCs $(n=19)$ and N-MSCs $(n=10)$. (B) Clonogenic capacity of L-MSCs $(n=15)$ and N-MSCs $(n=10)$ evaluated by CFU-F assay. (C) PDT of L-MSCs at P2 isolated from patients in complete remission $(n=8)$ or with disease progression $(n=11)$. $(\mathbf{D}$, left $)$ Representative images of flow cytometry analysis of CFSE MFI after 24 (dark gray) and 96 (light gray) h of staining. The difference between these two MFI values $(\Delta \mathrm{MFI})$ reflects the cell proliferative potential over $72 \mathrm{~h}$. (D, right) $\Delta \mathrm{MFI}$ values in L-MSCs $(n=5)$ and N-MSCs $(n=4)$. For symbols, see legend in Fig. 1. Horizontal bars represent the medians. $* P<0.05 ; * * P<0.01$; $* * * P<0.005$. PDT, population doubling time; CFU-F, colony-forming unit-fibroblast; MFI, mean fluorescence intensity.

showed decreased expression $(P<0.05)$ of genes encoding secreted cytokines, such as ANG-1 (ANGPT1), SCF $(K I T L G)$, and TPO (THPO), in L-MSCs compared with $\mathrm{N}-$ MSCs (Fig. 4A), while the expression of the genes encoding SDF-1 $\alpha$ (CXCL12), FLT3-Ligand (FLT3LG), and Jagged 1 (JAGl) was similar between groups. Conversely, the expression of genes encoding the adhesion molecules, integrin alpha 5 (CD49e/ITGA5) $(P<0.01)$ and melanoma cell adhesion molecule $(\mathrm{CD} 146 / M C A M)(P<0.05)$, was increased in L-MSCs compared with N-MSCs, whereas the genes encoding VCAM-1 (CD106/VCAM1) and integrin alpha 6 (CD49F/ITGA6) were downregulated $(P<0.05)$. Gene expression of MSC markers, such as ASMA (ACTA2), nestin $(N E S)$, and NGF receptor (CD271/NGFR), and of extracellular matrix molecules, such as fibronectin 1 (FN1), collagen 1A1 (COL1A1), 4A1 (COLAAl), and osteopontin (OPN/ SPP1), was not significantly different between groups. Among the other 60 genes (Supplementary Fig. S3A, B), genes involved in the osteogenic lineage, such as osteocalcin $(\mathrm{OCN} / B G L A P)$ and $R U N X 2$, or in the chondrogenic lineage (COL10A1) were downregulated in L-MSCs compared with N-MSCs $(P<0.05)$, whereas $B M P 1$ was upregulated $(P<0.05)$ and no change was observed in $P P A R G$, an adipogenic lineage gene. RUNX2 and BMP1 expression was inversely correlated $(\rho=-0.61 ; P<0.05)$. The expression of developmental/embryonic genes, such as OCT4/ POU5F1, SOX2, and NANOG, was unchanged, but for $B M I 1$ that was downregulated in L-MSCs $(P<0.05)$ as found for DICER1, a gene encoding a ribonuclease involved in the RNA interference pathway. However, the reduction of KITLG, ANGPT1, and THPO gene expression was not confirmed by ELISA analysis of secreted niche factors in LMSC and N-MSC supernatants (Fig. 4B-E). Likewise, increased CD49e and CD146 gene expression in L-MSCs was only associated with a tendency to increased membrane protein expression quantified by flow cytometry (Fig. 4F). Nevertheless, CD146 gene expression positively correlated with $\mathrm{CD} 49 \mathrm{e}$ protein expression $(\rho=0.74 ; P<0.01)$. It is noteworthy that CD146 protein expression level also positively correlated with BM leukoblast percentage in L-MSCs 
A

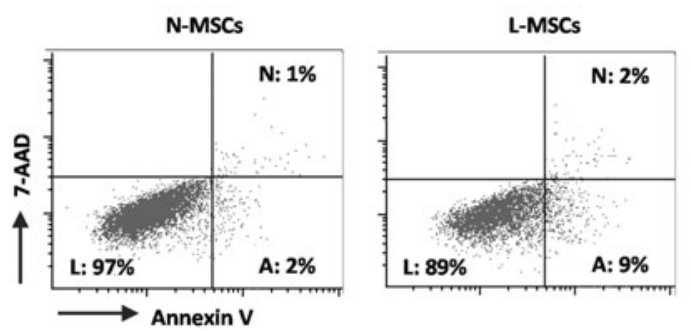

B

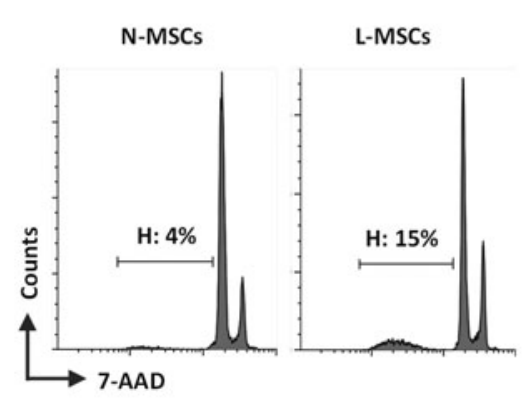

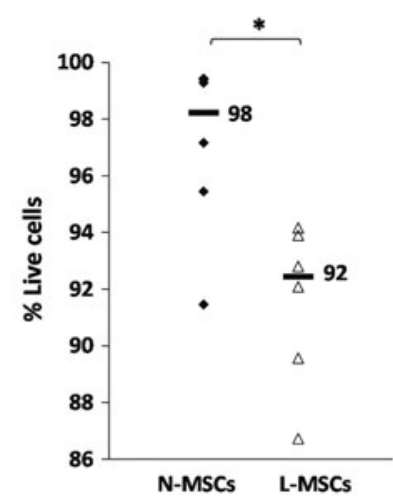
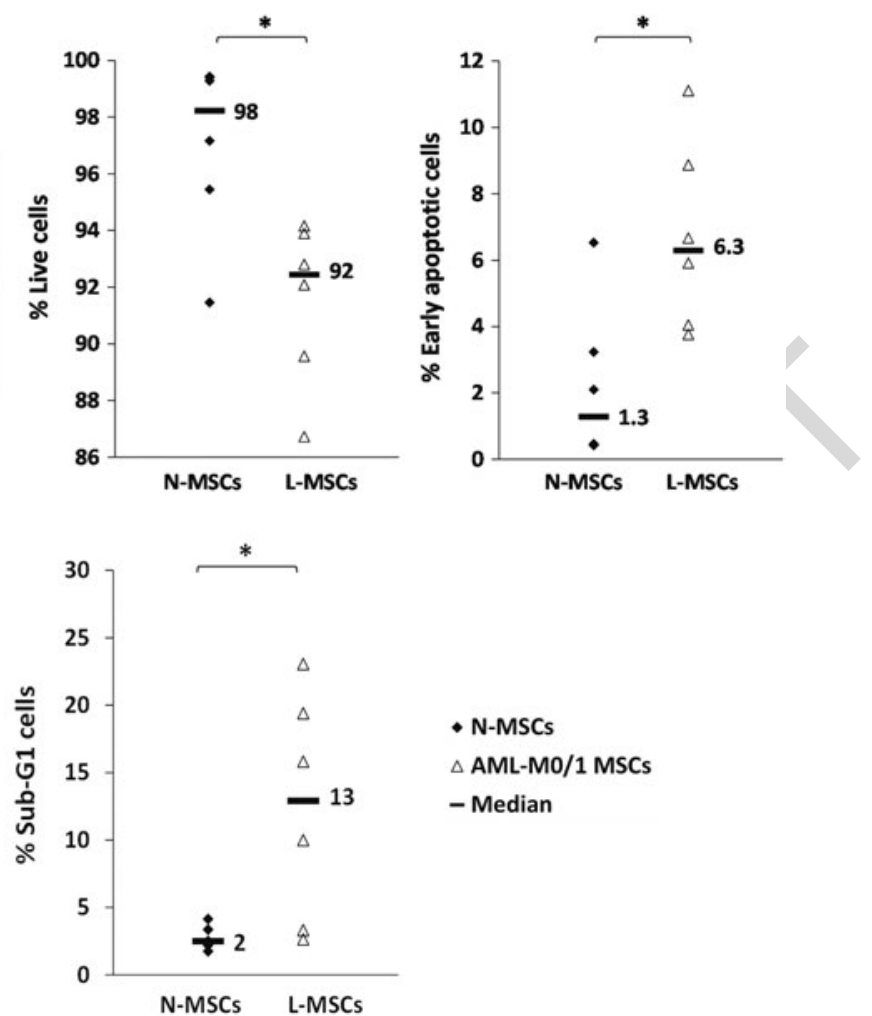

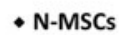

$\triangle \mathrm{AML}-\mathrm{MO} / 1 \mathrm{MSCS}$

- Median

FIG. 3. L-MSCs show higher apoptosis rates than N-MSCs. (A, left) Representative images of flow cytometry analysis of early apoptosis in MSCs. (B, right) Quantification of MSC apoptosis analysis expressed in percentage of live (7-AAD ${ }^{\text {neg }}$ / Annexin $\mathrm{V}^{\text {neg }}$ cells) and early apoptotic (7-AAD ${ }^{\text {neg }} /$ Annexin $\mathrm{V}^{\text {pos }}$ cells) cells for L-MSCs $(n=6)$ and N-MSCs $(n=6)$. (B, left) Representative flow cytometry analysis of late apoptosis in MSCs fixed and permeabilized before 7-AAD staining showing the presence of hypoploid $(\mathrm{H})$ cells (sub-G1). (B, right): Percentage of hypoploid cells in L-MSC ( $n=6)$ and N-MSC cultures $(n=6)$. Black diamonds, individual N-MSC samples; triangles, individual L-MSC samples from patients with AML-M0/1. Horizontal bars represent the medians. ${ }^{*} P<0.05$.

$(\rho=0.80 ; P<0.001)$ and inversely correlated with the patient age considering MSCs from leukemic patients, normal controls, or both $(\rho=0.63 ; P<0.001)$. CD106 protein (VCAM-1) expression was meanwhile significantly decreased in L-MSCs compared with N-MSCs $(P<0.05$; Fig. 4G), in accordance with the mRNA findings (Fig. 4A). No qualitative or quantitative differences between L-MSCs and N-MSCs in the extracellular matrix deposition of fibronectin and the intracellular expression of the cytoskeleton proteins ASMA and nestin were observed by immunofluorescence analysis (Fig. 5), according to the gene expression data (Fig. 4A).

Considering the wide variations found in L-MSC growth capacity, a relationship between this capacity and L-MSC phenotype was investigated. Thus, longer PDT was associated with lower expression of $R U N X 2(\rho=-0.64 ; P<0.05)$, COL10A1 $(\rho=-0.64 ; P<0.05)$, THPO $(\rho=-0.69 ; P<0.05)$, less secreted CXCL12 $(\rho=-0.69 ; P<0.05)$, and with higher expression of BMP1 $(\rho=0.75 ; P<0.01)$, ITGA5 $(\rho=0.90$; $P<0.001)$, and JAG1 $(\rho=0.69 ; P<0.05)$. Same correlations were also found for lower clonogenicity (CFU-F) with lower expression not only of RUNX2 $(\rho=0.67 ; \quad P<0.05)$, COL10A1 $(\rho=0.80 ; P<0.01)$, THPO $(\rho=0.63 ; P<0.05)$, and CXCL12 $(\rho=0.62 ; P<0.05)$ [as for secreted CXCL12 $(\rho=0.64 ; P<0.05)]$ but also ANGPT1 $(\rho=0.64 ; P<0.05)$ and with higher expression of $B M P 1(\rho=-0.57 ; P=0.05)$, ITGA5 $(\rho=-0.65 ; P<0.05)$, and JAG1 $(\rho=-0.72 ; P<0.01)$.
Moreover, increased level of senescence was associated with lower expression of RUNX2 $(\rho=-0.81 ; P<0.01)$, COL10A1 $(\rho=-0.82 ; P<0.01)$, ITGA4 $(\rho=-0.75 ; \quad P<$ 0.01), DICER1 $(\rho=-0.72 ; P<0.05)$, BMII $(\rho=-0.70 ; P<$ $0.05)$, and especially ANGPT1 $(\rho=-0.88 ; P<0.001)$. Senescence entry also correlated with lower clonogenicity of L-MSCs $(\rho=-0.80 ; P<0.01)$. The existence of a strong positive relationship between gene expression of DICERI and BMII $(\rho=0.97 ; P<0.00001)$ is noteworthy.

\section{MSCs from patients with $A M L$ retain normal hematopoietic supportive function}

The hematopoiesis-supporting capacity of confluent LMSCs and N-MSCs was tested by using Dexter-type longterm cocultures recharged with normal $\mathrm{CD} 34^{\text {pos }}$ cells for 5 weeks. To limit patient heterogeneity, we focused this study on L-MSCs from patients with AML-M0/1 (L-MSCs a, b, c, d). Weekly assessment of the HPC number in supernatants was not significantly different in L-MSC and N-MSC cocultures (Fig. 6A). Similar findings were obtained when the total HPC production from adherent and nonadherent cell fractions was evaluated at the end of week 5 (Fig. 6B). The microscopic visualization of cobblestone areas in both LMSC and N-MSC cocultures at week 5 also supported these results (Fig. 6C). The normal hematopoietic supportive function of L-MSCs cannot be explained only by biased 

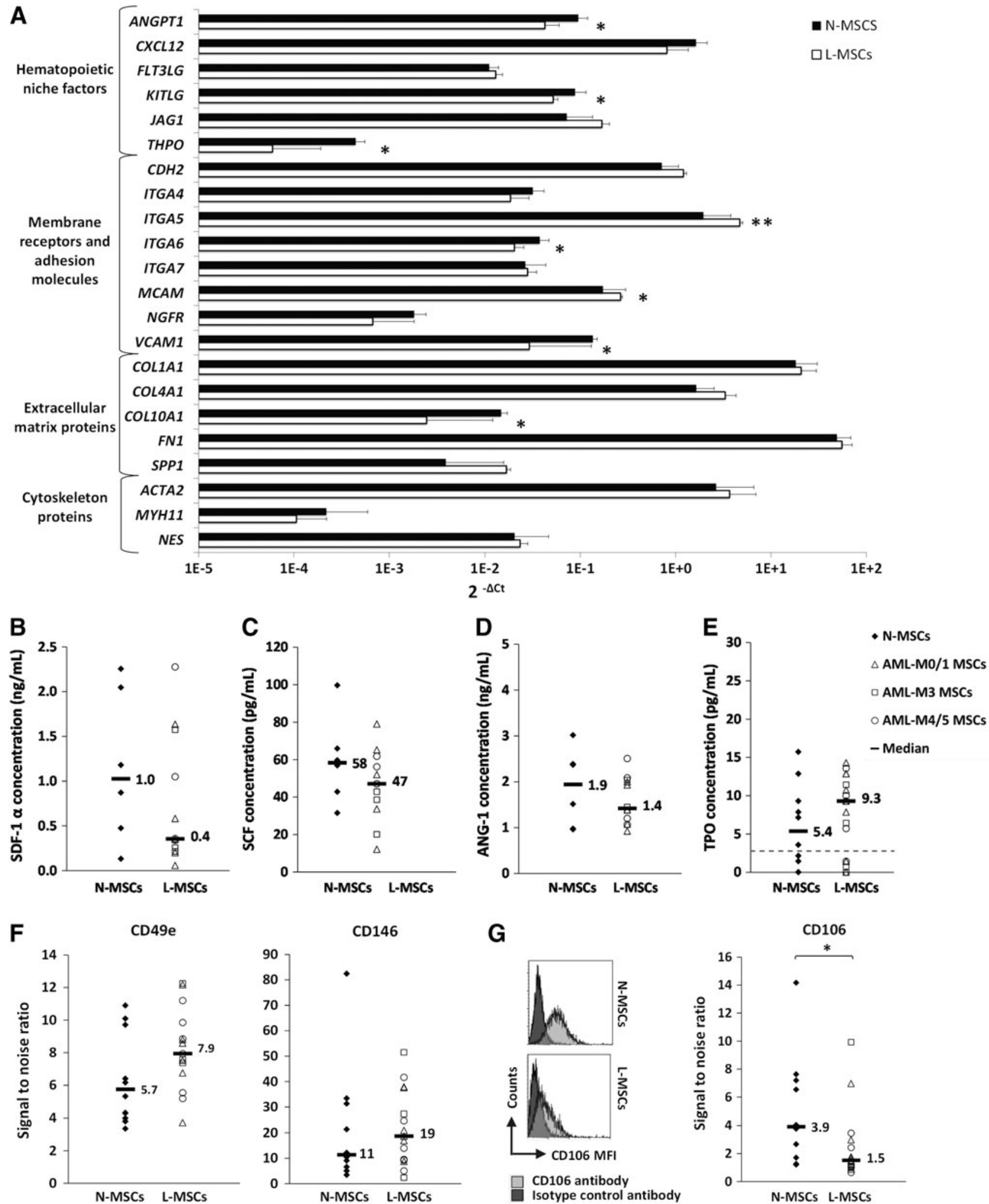

FIG. 4. The expression of niche factors is altered in L-MSCs. (A) Transcriptional profile of 22 niche-related genes in L-MSCs $(n=12)$ and N-MSCs $(n=6)$. Values represent the relative expression $\left(2^{-\Delta C t}\right.$ value) of each gene normalized to a computed endogenous control (aggregated median of B2M and EIF $2 B 1$ expression). Bars, medians; and error bars, semi-interquartile ranges. (B-E) Protein expression of the secreted niche factors SDF-1 $\alpha$, SCF, and ANG-1 measured by enzyme-linked immunosorbent assay in supernatants from L-MSC $(n=12)$ and N-MSC $(n=6)$ samples; for TPO: L-MSCs $(n=19)$ and N-MSCs $(n=10)$. (F, G) Expression levels of membrane receptors and adhesion molecules measured by flow cytometry in L-MSC $(n=15)$ and N-MSC $(n=10)$ samples. Signal-to-noise ratio: ratio between the median fluorescence intensities (MFIs) for the specific and isotypematched control antibodies. CD49e (integrin alpha 5) and CD146 (MCAM) expression was evaluated by direct staining (F) and CD106 (VCAM-1) by indirect staining $(\mathbf{G})$. For symbols, see legend in Fig. 1. Horizontal bars represent the medians. $* P<0.05$; $* * P<0.01$. SDF-1 $\alpha$, stromal cell-derived factor-1 alpha; SCF, stem cell factor; ANG-1, angiopoietin-1; TPO, thrombopoietin. 
FIG. 5. The expression of fibronectin, ASMA, and nestin is comparable in L-MSC and N-MSC cultures. Representative microphotographs of N-MSC and L-MSC cultures after indirect immunofluorescence staining (green) with anti-fibronectin (L-MSCs, $n=10$; N-MSCs, $n=9$ ), ASMA $(\mathrm{L}-\mathrm{MSCs}=10 ; \mathrm{N}$ MSCs $=5$ ), and -nestin antibodies (LMSCs $=6$; N-MSCs =6). Cell nuclei were stained with DAPI (blue). Scale bars $=100 \mu \mathrm{m}$. ASMA, alpha smooth muscle actin.
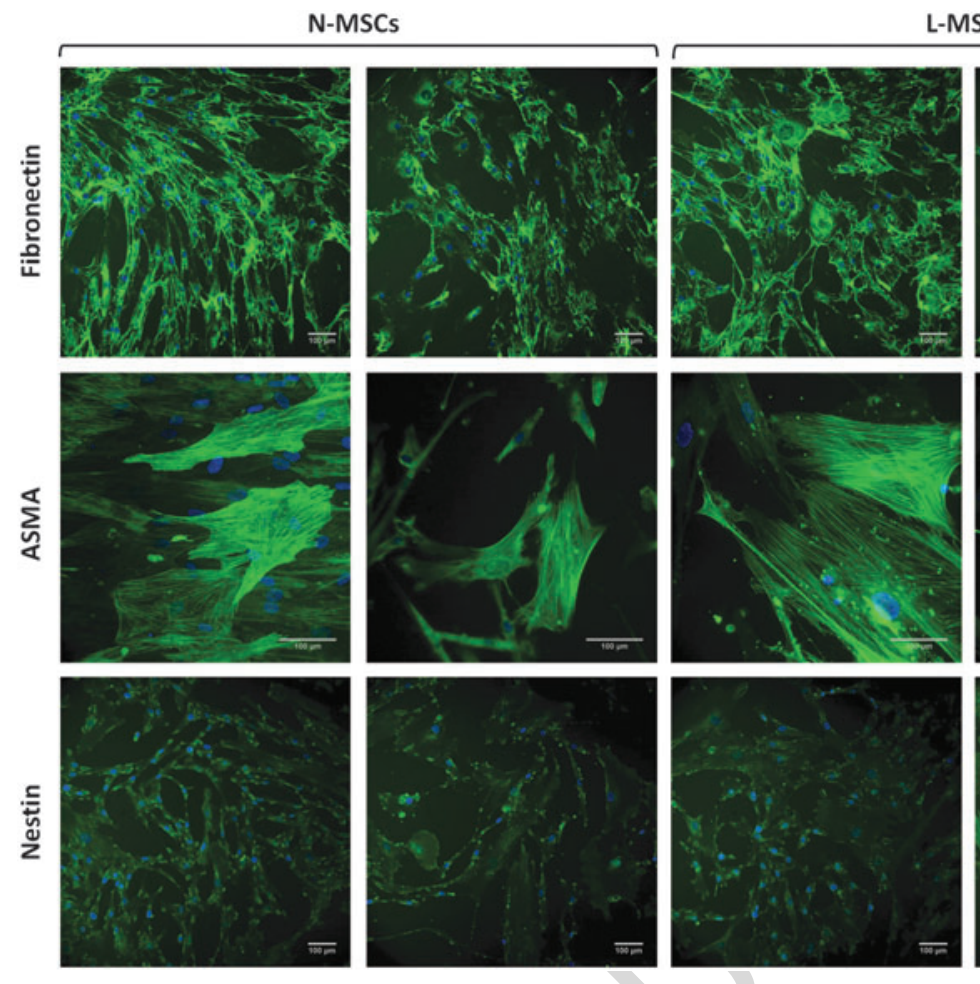

L-MSCs
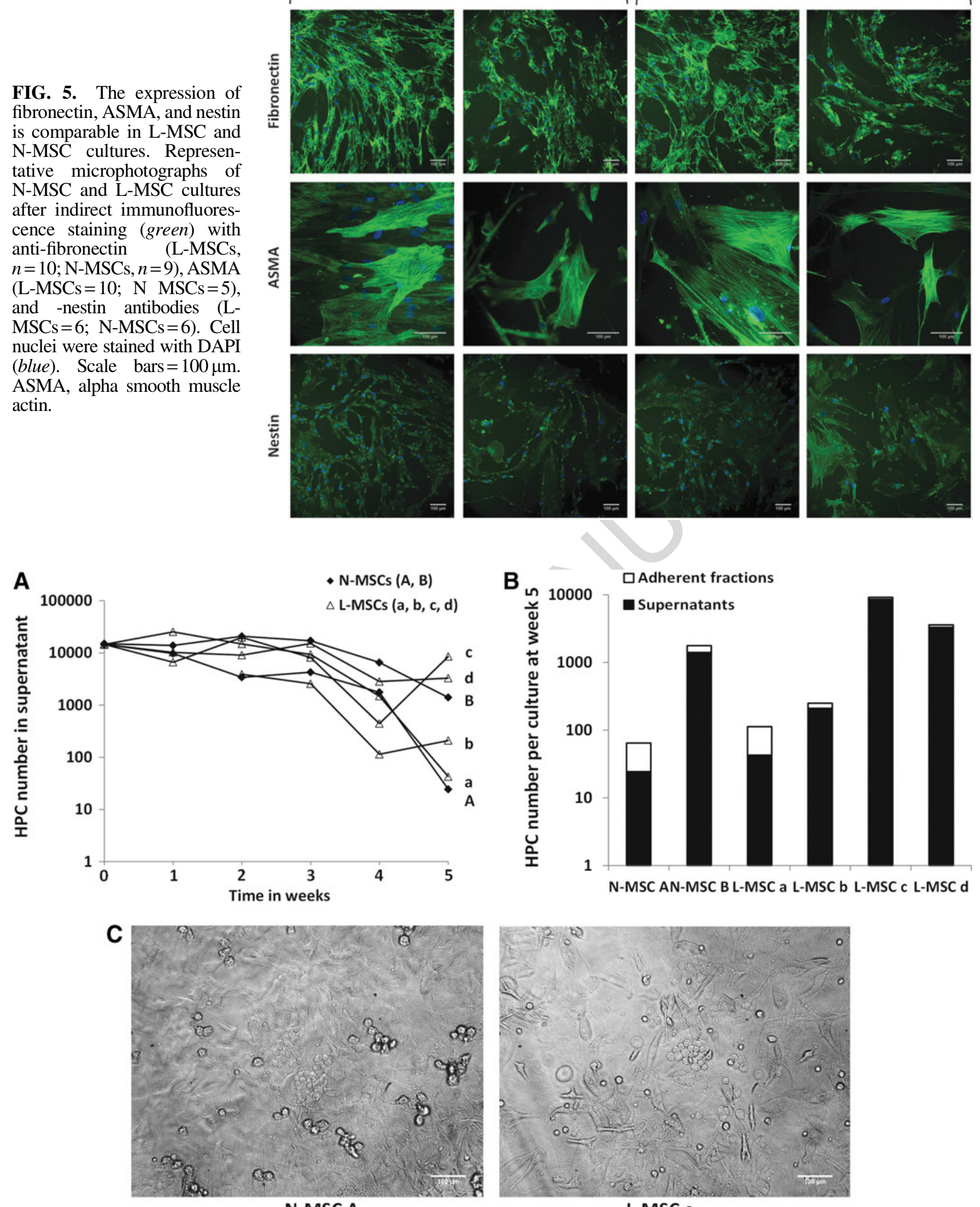

L-MSC c

FIG. 6. L-MSCs show normal hematopoietic supportive functions. (A, B) Dexter-type long-term cultures were performed in which CD34+ cells were cocultured on confluent layers of 10-Gy irradiated MSCs from patients with AML (L-MSCs; a, b, c, d) or from controls (N-MSCs; A, B) for 5 weeks. HPC production in the coculture supernatants was assessed weekly (A), and at the end of week 5, total HPC production was measured in the adherent and nonadherent cell fractions (B). (C): Cobblestone area formation observed at the end of week 5 in both N-MSC (subject A) and L-MSC (patient c) layers. Scale bars $=100 \mu \mathrm{m}$. HPC, hematopoietic progenitor cell. 
selection of normal cell layers. Indeed, L-MSC d showed one of the best supporting activities while having one of the longest PDT.

\section{MSCs from patients with AML directly influence the behavior of leukemic cells as observed with normal MSCs}

The capacity of L-MSCs and N-MSCs to modify leukemic cell behavior was compared by coculturing MSCs with KG1a cells and primary blast cells (AML-M0/1) in heterologous (hetero) and autologous (auto) settings for 2-3 days. The fraction of adherent leukemic cells was not significantly different in cultures of KG1a or primary blast cells with LMSCs and N-MSCs, as well as in auto and hetero settings (data not shown). The elevated early apoptosis rate of primary blast cells $\left(7-\mathrm{AAD}^{\text {neg }} /\right.$ Annexin $\left.\mathrm{V}^{\mathrm{pos}}\right)$ observed in MSC-free cultures was significantly and similarly reduced $(p<0.05)$ when they were cocultured with L-MSCs or NMSCs (Fig. 7A, B). Similar results were obtained when late apoptosis (cells in sub-G1) was analyzed (data not shown). Again, results were comparable when using auto and hetero L-MSCs. Moreover, cell cycle analysis indicated that the fraction of $\mathrm{KG1a}$ cells in $\mathrm{G} 0\left(7-\mathrm{AAD}^{\text {low }} / \mathrm{Ki}-67^{\text {neg }}\right)$ was clearly increased in the presence of both L-MSCs and NMSCs (Fig. 7C) in the whole KG1a population $(P<0.01)$ and particularly in adherent cells $(P<0.01)$ (Supplementary Fig. S4). Similar results were observed using primary blast cells $(P<0.05$; Fig. 7D). MSC effect on cell cycle exit of primary blast cells was comparable when cocultured with auto or hetero L-MSCs. Moreover, quiescence of blast cells by direct contact with MSCs (N-MSCs or auto and hetero LMSCs) was associated with a slight decrease in anti- $\gamma \mathrm{H} 2 \mathrm{AX}$ staining (a marker of DNA DSBs) compared with MSC-free cultures $(P<0.01)$ (Fig. 7E), consistent with the previously reported relationship between DNA damage level and cell cycle entry [29].

\section{Discussion}

This study shows that MSCs isolated from the BM of patients with newly diagnosed de novo AML display some alterations, including reduced proliferation capacity, increased apoptosis, and decreased expression of several niche-related factors, such as SCF, TPO, ANG-1, and VCAM-1, compared with MSCs from controls. Proliferation deficiency of L-MSCs was not related to AML characteristics at diagnosis (FAB type, cytogenetics, or tumor burden), but was independently associated with poorer patient outcome, as was cytogenetic prognostic feature. This defect was correlated with an MSC perivascular feature at the expense of the osteo-chondroblastic lineage and with lower niche factor and higher JAGl expression. However, these changes are not sufficient to modify L-MSC in vitro capacity to support normal hematopoiesis and to influence the behavior of leukemic cells in vitro.

The main abnormality detected in L-MSCs was a clear decrease in their proliferative potential, as recently reported in AML $[9,10,12-14]$. Such proliferation defects have also been described in MSCs from several other hematopoietic disorders, such as acute lymphoblastic leukemia (ALL) [31,32], chronic lymphocytic leukemia (CLL) [33,34], and especially MDS $[16,17,35,36]$. A slight decrease of their clonogenic potential (CFU-F) was also observed that was inversely correlated with the PDT values. The mechanisms of MSC proliferation impairment at the onset of leukemia are still unclear. The role of leukemic cells on BM-derived MSC proliferation appears undeniable, as demonstrated by in vitro studies with cell supernatants [12,37] that also are able to inhibit osteoblastic differentiation [12]. A recent report showed a specific influence of leukemic CD34+ cells (compared with normal $\mathrm{CD} 34+$ cells) cocultured on $\mathrm{N}$ MSCs by a transcriptomic approach, including downregulation of cell cycle and related function genes [13]. In vivo studies clearly showed that AML development in mice disrupts the BM microenvironment, resulting in fewer endosteal osteoblasts and more osteoclasts [38], and that osteoblast ablation accelerates CML development [39]. Such changes have been described also in preleukemic disease models [24-26].

Moreover, L-MSC growth impairment can be restored with the repetition of chemotherapy cycles [32] or at diagnosis when most leukemic cells are eliminated by immunoselection of CD105 ${ }^{\text {pos }}$ MSCs [10]. It has been shown that fragmented DNA released by AML cells may enter MSC nuclei and induce DNA DSBs and cell death [40]. Accordingly, we found increased early and late apoptosis rates in L-MSCs (as reported in CLL [33]), while DNA DSB presence, cell senescence, intracellular ROS production, and telomere length were unchanged. The lack of relationship between decreased MSC proliferative capacity and telomere length has already been reported [41] and is probably due to the use of MSCs after limited passages (P2).

An original data item of our study is the identification of L-MSC proliferative capacity (based on PDT evaluation) as a strong independent prognostic factor for patient outcome (besides cytogenetic prognostic feature, as expected), which was not found for leukemia FAB type or tumor burden. Thus, a longer PDT might highlight the presence of a leukemic clone with a particular toxicity and aggressiveness toward the BM stromal compartment.

L-MSC proliferative deficiency was associated with other abnormal phenotypic features. Particularly, expression of the genes encoding the cytokines ANG-1, SCF, and TPO, as well the adhesion molecule VCAM-1, was downregulated in L-MSCs. This decrease was confirmed for VCAM-1 protein membrane expression. Such results are consistent with a recent report showing that sorted BM stromal cells from a mouse model of AML express lower levels of Vcaml, Cxcl12, Angpt1, and Scf transcripts [21]. Downregulation of SCF and/or ANG-1 expression has also been described in MSCs from patients with AML [12] and MDS [16,17].

Furthermore, both CD146/MCAM (a perivascular marker of MSCs) and CD49e/ITGA5 (the main ligand for fibronectin) were upregulated in L-MSCs, as reported in patients with MDS [16] and primary myelofibrosis [42] and in mice with chemically induced leukemia [43]. Despite ITG5A upregulation in L-MSCs, extracellular deposition of fibronectin (its ligand) was comparable in L- and N-MSCs. An over-representation of the CD146 ${ }^{\mathrm{pos}}$ MSC subpopulation in leukemic BM may reflect changes in MSC distribution in favor of perisinusoidal sites [44] where reticular cells coexpress CD271 and CD146 antigens [45]. The positive correlation between CD146 and CD49e expression levels is consistent with this hypothesis since increased alpha5 
A

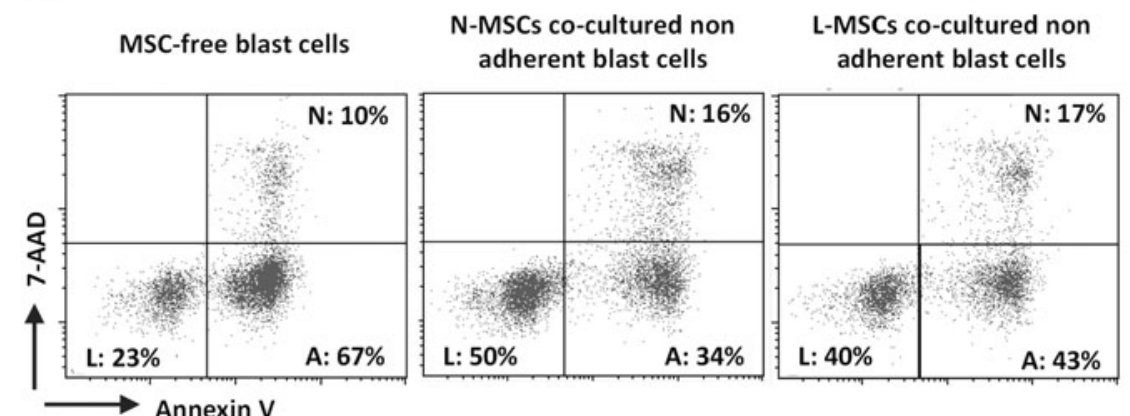

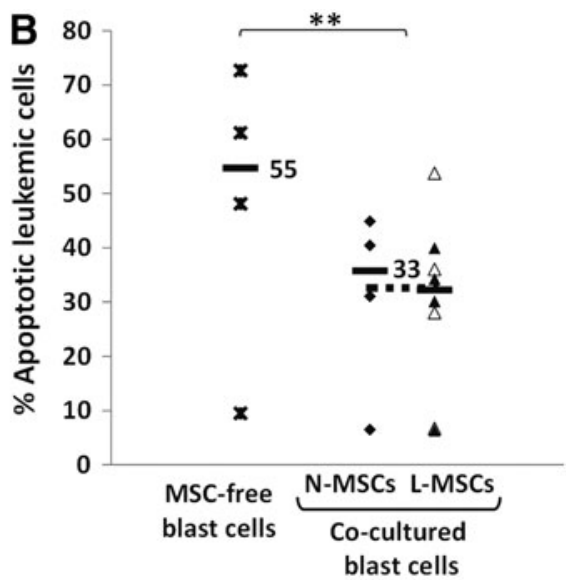

C

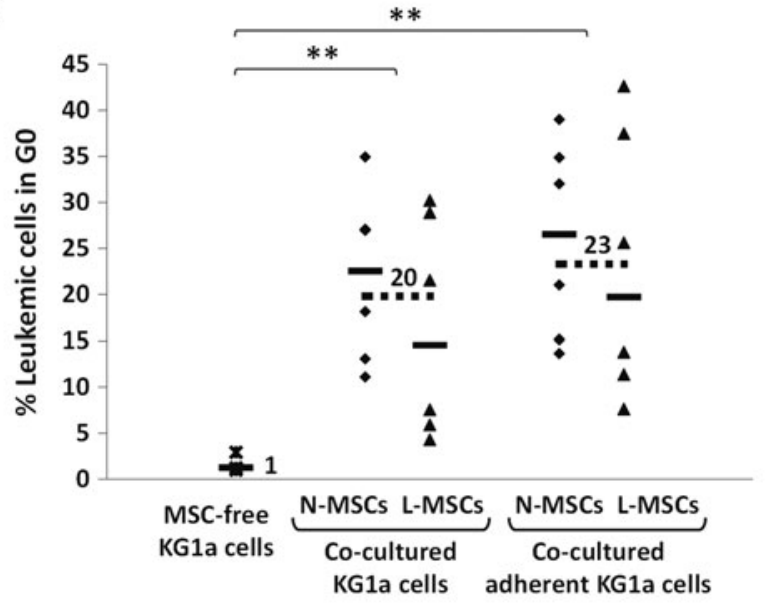

D
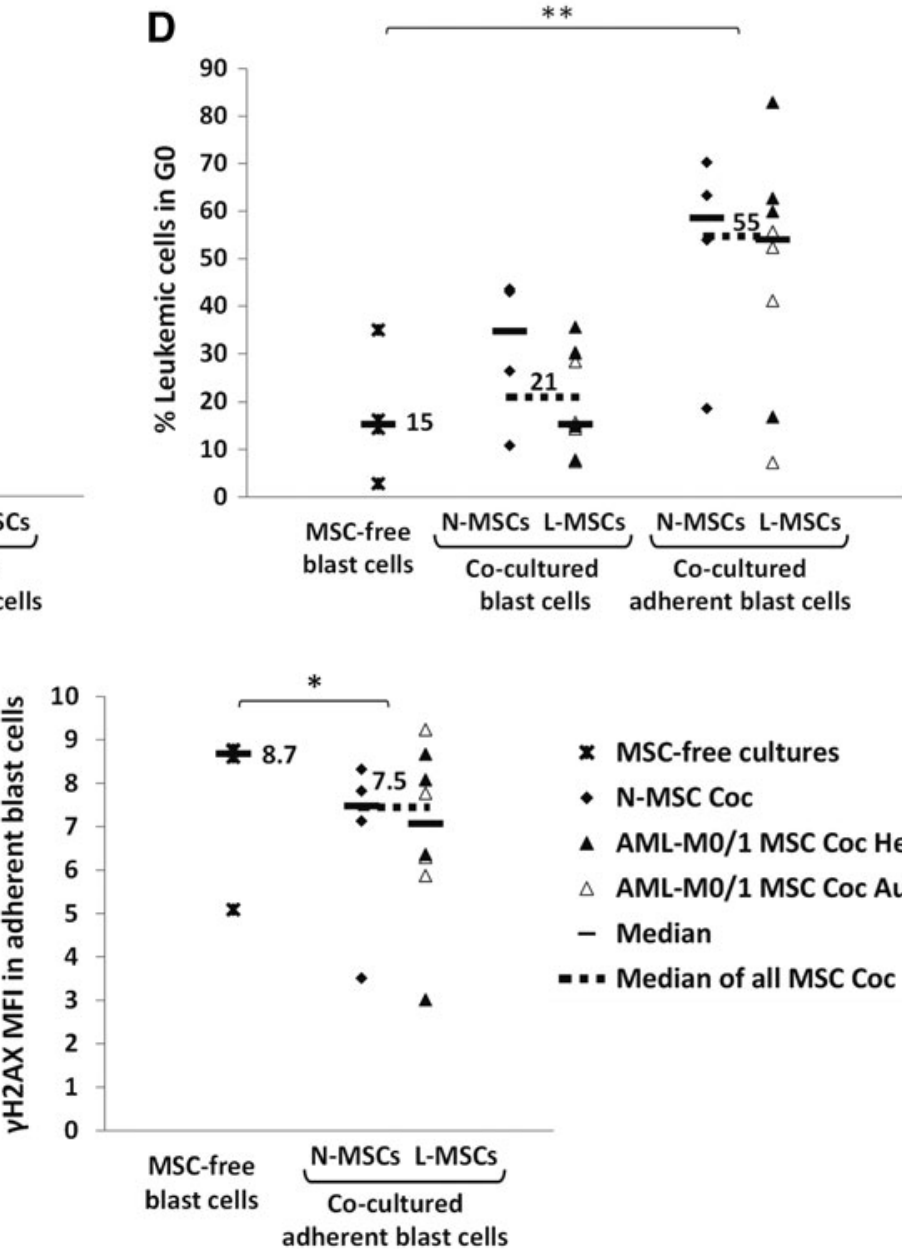

x MSC-free cultures

- N-MSC Coc

- AML-M0/1 MSC Coc Hetero

$\triangle$ AML-MO/1 MSC Coc Auto

- Median

-. Median of all MSC Coc
L-MSCs co-cultured adherent blast cells

N-MSCs co-cultured

adherent blast cells

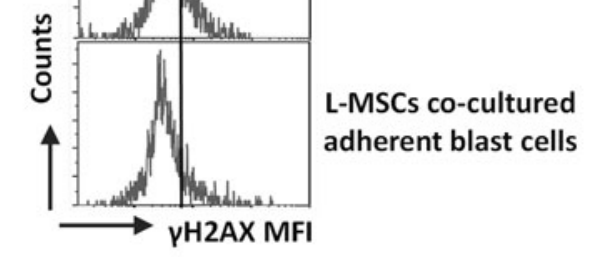

FIG. 7. L-MSCs and N-MSCs protect leukemic cells from apoptosis and promote their quiescence in a similar manner. Cocultures of KG1a cells or primary blast cells (AML-M0/1) with L-MSCs (AML-M0/1) or N-MSCs for 2-3 days. Blast cells were cocultured either with heterologous (Coc Hetero) or autologous (Coc Auto) L-MSCs. Leukemic cells (CD45 $5^{\text {pos }}$ cell fraction) were analyzed by flow cytometry. For each experiment, one L-MSC coculture with KG1a cells $(n=6)$ or primary blast cells $(n=8)$ was matched with one N-MSC coculture with KG1a cells $(n=6)$ or primary blast cells $(n=4)$ and both compared with KG1a cells $(n=3)$ and primary blast cells $(n=4)$ cultured without MSCs. (A) Representative images of apoptosis quantification in primary blast cells cocultured or not with MSCs determined by Annexin V/7-AAD staining. (B) Individual percentages of apoptotic $\left(\mathrm{AAD}^{\text {neg }}\right.$ Annexin $\mathrm{V}^{\mathrm{pos}}$ ) primary blast cells. $(\mathbf{C}$, D) Cell cycle analysis after 7-AAD/Ki67 staining. Quantification of KG1a (C) and primary blast (D) cells in G0 (7-AAD ${ }^{\text {low }} / \mathrm{Ki}^{-67^{\text {neg }}}$ ) cells. (E) Representative images of DNA double-strand break detection in primary blast cells cocultured or not with MSCs by anti- $\gamma \mathrm{H} 2 \mathrm{AX}$ staining (E, left); quantification of DNA double-strand breaks, as indicated by the MFIs of $\gamma \mathrm{H} 2 \mathrm{AX}$ staining, in adherent primary blast cells (E, right). Crosses, MSC-free cultures; black diamonds, cocultures with N-MSCs; black triangles, cocultures with heterologous L-MSCs; empty triangles, cocultures with autologous L-MSCs. Horizontal bars represent the medians. $* P<0.05 ; * * P<0.01$ 
integrin expression has been associated with pericyte differentiation [46]. In accordance with a report showing that leukemic proliferation in a mouse model can induce deficiency of osteoblastic cells [38], our study shows a concomitant lower expression of osteogenic (OCN, RUNX2) differentiation genes in L-MSCs, as reported in humans with MDS [17,47] and more recently in AML [12]. In addition to these data, our finding that CD146 levels in L-MSCs correlated with the degree of $\mathrm{BM}$ leukoblast infiltration argues for leukemia-induced changes in BM MSC distribution in favor of perisinusoidal sites at the expense of endosteal sites. The inverse correlation we observed between CD146 protein expression levels and age is consistent with a report showing in elderly people a decrease of the BM CD146 cell population in favor of CD146 ${ }^{\text {neg }}$ MSCs [48].

Considering the phenotypic changes observed in LMSCs, we investigated whether they were related to their growth capacities and senescence levels. Thus, prolonged PDT and decreased clonogenic potential were associated with a particular MSC phenotype, including lower expression of osteogenic (RUNX2) and chondrogenic (COL1OA1) markers, as well as of the niche factors, THPO, CXCL12, and $A N G P T 1$, and higher expression of BMP1, ITGA5, and $J A G 1$. The latter gene (which encodes the protein Jagged 1) has been shown to be associated with breast cancer development [49] and involved in BM stroma-dependent AML induction [50] and chemoresistance [51]. In these conditions, the independent prognostic value of MSC PDT found in our study, which was negatively correlated with JAG1 gene expression, appears of particular interest. This must be compared with the higher Jagged 1 expression on L-MSCs than on N-MSCs, as previously reported [12,49]. Anyway, the direct involvement of Jagged 1 in L-MSC proliferation needs to be elucidated.

Likewise, senescence levels of L-MSCs (that increased with lower clonogenic potential) were associated with lower gene expression of RUNX2,COL1OA1, and ANGPT1 and particularly of DICERI and BMI1 whose expression levels were strongly correlated with each other. Our study extends to AML patients' DICER1 downregulation previously reported in MSCs from MDS patients [52]. Additionally, the inverse relationship between DICER1 or BMI1 expression and senescence levels in L-MSCs is consistent with the role of both factors recently shown to protect MSCs from senescence $[53,54]$.

Finally, we evaluated whether L-MSC abnormalities had an effect on their supportive function on normal and leukemic hematopoiesis. The capacity to support normal hematopoiesis, assessed by Dexter-type long-term cultures, was comparable in L-MSCs (only from patients with AMLM0/1 for better homogeneity) and N-MSCs. These results were confirmed by the observation of HPC production by adherent layers and cobblestone area formation at week 5 . Of note, L-MSC hematopoiesis-supporting activity was normal regardless of their proliferative capacity and despite lower VCAM-1 expression. Normal HPC production has also been reported in a previous study using immunoselected AMLMSCs [10], in contrast to other studies where different (sometimes suboptimal) culture conditions of MSCs were used $[9,12,55]$. Our findings are consistent with a very recent study in a murine model of AML indicating that BM microenvironment retains in vivo supporting activity of normal hematopoiesis [56]. Normal supporting activity of MSCs from patients with hematological malignancies was also shown in CML [18], myeloma [57], and lymphoma [9], whereas impaired function has been reported in ALL [31,32], CLL [34], and particularly MDS [15-17,35,36,58].

N-MSCs are also known to protect leukemic cells (particularly in AML) from apoptosis, favor their chemoresistance, and induce their quiescence $[3,4,59,60]$. In this study, we show that L-MSCs and N-MSCs similarly decrease the levels of early and late apoptotic leukemic cells and increase the proportion of leukemic cells in $G_{0}$ associated with a slight decrease in DNA DSB levels. Moreover, when comparing the results of matched autologous and heterologous cocultures of L-MSCs and primary blast cells, we did not find any significant difference. Our data are in accordance with a very recent study in which rates of in vivo engraftment of primary blast cells were not different when previously cocultured on L-MSCs and N-MSCs [13].

To explain the normal supportive function of L-MSCs found in our work, the selection of MSC subsets is not totally excluded, possibly favored by our culture conditions, in which the use of FGF2-supplemented MSC medium is certainly not negligible. On another side, it is conceivable that properties of MSCs from de novo AML patients at the onset of their disease are quite different than those from patients with other chronic hematological disorders, such as MDS. In these diseases, the well-known, long-term, and stronger impairment of the stromal cell compartment in a chronic inflammatory context could even promote the leukemia emergence [61].

In conclusion, our study highlights some changes of the stromal cell compartment during AML cell expansion. They include proliferation deficiency, increased apoptosis, downregulation of several niche-related factors, and a tendency to exhibit a perivascular feature at the expense of the osteo-chondroblastic lineage. However, all these changes were not associated with altered MSC supporting function on normal and leukemic hematopoiesis in vitro. Finally, these findings suggest that the impairment of BMderived MSCs observed at the onset of de novo AML does not play a special role in the leukemic process.

\section{Acknowledgments}

This work was supported by the French "Conseil Régional du Centre", the French Ministry of Research, the National Center of Scientific Research (CNRS), the "Cancéropôle Grand-Ouest" network (NICHEMOPATH Project), and the charities "Les Sapins de l'Espoir Contre le Cancer", "CANCEN," and Rotary International (club of Blois). The authors would particularly like to thank Prof. Philippe Rosset for having provided the bone marrow samples as well as Marion Thévenot, Sophie Lagrange, Audrey Gauthier, Sophie Hamard, Emmanuel Pecnard, and Marie-Christine Bernard from the LNOx team (CNRS UMR 7292) for their help in culturing and analyzing human BMderived MSCs and Christophe Arnoult, from the antibodies, Fc receptors and clinical responses team (CNRS UMR 7292), for his expert assistance on flow cytometry analyses.

\section{Author Disclosure Statement}

No competing financial interests exist. 


\section{References}

1. Ferrara F and C Schiffer. (2013). Acute myeloid leukaemia in adults. Lancet 381:484-495.

2. Dick JE. (2008). Stem cell concepts renew cancer research. Blood 112:4793-4807.

3. Garrido SM, FR Appelbaum, CL Willman and DE Banker. (2001). Acute myeloid leukemia cells are protected from spontaneous and drug-induced apoptosis by direct contact with a human bone marrow stromal cell line (HS-5). Exp Hematol 29:448-457.

4. Konopleva M, S Konoplev, W Hu, AY Zaritskey, BV Afanasiev and M Andreeff. (2002). Stromal cells prevent apoptosis of AML cells by up-regulation of anti-apoptotic proteins. Leukemia 16:1713-1724.

5. Costello RT, F Mallet, B Gaugler, D Sainty, C Arnoulet, JA Gastaut and D Olive. (2000). Human acute myeloid leukemia CD34+/CD38- progenitor cells have decreased sensitivity to chemotherapy and Fas-induced apoptosis, reduced immunogenicity, and impaired dendritic cell transformation capacities. Cancer Res 60:4403-4411.

6. Dennis JE and P Charbord. (2002). Origin and differentiation of human and murine stroma. Stem Cells 20:205-214.

7. Caplan AI. (1991). Mesenchymal stem cells. J Orthop Res 9:641-650.

8. Prockop DJ. (1997). Marrow stromal cells as stem cells for nonhematopoietic tissues. Science 276:71-74.

9. Zhao ZG, Y Liang, K Li, WM Li, QB Li, ZC Chen and P Zou. (2007). Phenotypic and functional comparison of mesenchymal stem cells derived from the bone marrow of normal adults and patients with hematologic malignant diseases. Stem Cells Dev 16:637-648.

10. Campioni D, F Lanza, S Moretti, M Dominici, M Punturieri, S Pauli, T Hofmann, E Horwitz and GL Castoldi. (2003). Functional and immunophenotypic characteristics of isolated CD105(+) and fibroblast $(+)$ stromal cells from AML: implications for their plasticity along endothelial lineage. Cytotherapy 5:66-79.

11. Mayani H. (1996). Composition and function of the hemopoietic microenvironment in human myeloid leukemia. Leukemia 10:1041-1047.

12. Geyh S, M Rodríguez-Paredes, P Jäger, C Khandanpour, RP Cadeddu, J Gutekunst, CM Wilk, R Fenk, C Zilkens, et al. (2016). Functional inhibition of mesenchymal stromal cells in acute myeloid leukemia. Leukemia 30:683-691.

13. Kim JA, JS Shim, GY Lee, HW Yim, TM Kim, M Kim, SH Leem, JW Lee, CK Min and IH Oh. (2015). Microenvironmental remodeling as a parameter and prognostic factor of heterogeneous leukemogenesis in acute myelogenous leukemia. Cancer Res 75:2222-2231.

14. Chandran P, Y Le, Y Li, M Sabloff, J Mehic, M RosuMyles and DS Allan. (2015). Mesenchymal stromal cells from patients with acute myeloid leukemia have altered capacity to expand differentiated hematopoietic progenitors. Leuk Res 39:486-493.

15. Zhao ZG, W Xu, HP Yu, BL Fang, SH Wu, F Li, WM Li, QB Li, ZC Chen and P Zou. (2012). Functional characteristics of mesenchymal stem cells derived from bone marrow of patients with myelodysplastic syndromes. Cancer Lett 317:136-143.

16. Ferrer RA, M Wobus, C List, R Wehner, C Schönefeldt, B Brocard, B Mohr, M Rauner, M Schmitz, et al. (2013). Mesenchymal stromal cells from patients with myelodyplastic syndrome display distinct functional alterations that are modulated by lenalidomide. Haematologica 98: 1677-1685.

17. Geyh S, S Oz, RP Cadeddu, J Fröbel, B Brückner, A Kündgen, R Fenk, I Bruns, C Zilkens, et al. (2013). Insufficient stromal support in MDS results from molecular and functional deficits of mesenchymal stromal cells. Leukemia 27:1841-1851.

18. Jootar S, N Pornprasertsud, S Petvises, B Rerkamnuaychoke, S Disthabanchong, S Pakakasama, A Ungkanont and S Hongeng. (2006). Bone marrow derived mesenchymal stem cells from chronic myeloid leukemia $t(9 ; 22)$ patients are devoid of Philadelphia chromosome and support cord blood stem cell expansion. Leuk Res 30:1493-1498.

19. Estrada-González PK, L Gómez-Ceja, JJ Montesinos, H Mayani, A Chávez-González, L Meillón, N Delgado, E Sánchez-Nava and E Flores-Figueroa. (2014). Decreased frequency, but normal functional integrity of mesenchymal stromal cells derived from untreated and Imatinib-treated chronic myeloid leukemia patients. Leuk Res 38:594-600.

20. Colmone A, M Amorim, AL Pontier, S Wang, E Jablonski and DA Sipkins. (2008). Leukemic cells create bone marrow niches that disrupt the behavior of normal hematopoietic progenitor cells. Science 322:1861-1865.

21. Hanoun M, D Zhang, T Mizoguchi, S Pinho, H Pierce, Y Kunisaki, J Lacombe, SAA Armstrong, U Dührsen and PSS Frenette. (2014). Acute myelogenous leukemia-induced sympathetic neuropathy promotes malignancy in an altered hematopoietic stem cell niche. Cell Stem Cell 15:1-11.

22. Hertenstein B, L Hambach and A Bacigalupo. (2005). Development of leukemia in donor cells after allogeneic stem cell transplantation-a survey of the European Group for Blood and Marrow Transplantation (EBMT). Haematologica 90:969-975.

23. Sala-Torra O, C Hanna, MR Loken, MED Flowers, M Maris, PA Ladne, JR Mason, D Senitzer, R Rodriguez, et al. (2006). Evidence of donor-derived hematologic malignancies after hematopoietic stem cell transplantation. Biol Blood Marrow Transplant 12:511-517.

24. Walkley CR, JM Shea, NA Sims, LE Purton and SH Orkin. (2007). Rb regulates interactions between hematopoietic stem cells and their bone marrow microenvironment. Cell 129:1081-1095.

25. Walkley CR, GH Olsen, S Dworkin, SA Fabb, J Swann, GA McArthur, SV Westmoreland, P Chambon, DT Scadden and LE Purton. (2007). A microenvironment-induced myeloproliferative syndrome caused by retinoic acid receptor gamma deficiency. Cell 129:1097-1110.

26. Raaijmakers MH, S Mukherjee, S Guo, S Zhang, T Kobayashi, JA Schoonmaker, BL Ebert, F Al-Shahrour, RP Hasserjian, et al. (2010). Bone progenitor dysfunction induces myelodysplasia and secondary leukaemia. Nature 464:852-857.

27. Herault O, J Domenech, M Degenne, JL Bremond, L Sensebe, MC Bernard, C Binet and P Colombat. (1998). All-trans-retinoic acid up-regulates CD38 but not c-Kit antigens on human marrow CD34+ cells without recruitment into cell cycle. Br J Haematol 103:343-350.

28. Herault O, P Colombat, J Domenech, M Degenne, JL Bremond, L Sensebe, MC Bernard and C Binet. (1999). A rapid single-laser flow cytometric method for discrimination of early apoptotic cells in a heterogenous cell population. Br J Haematol 104:530-537.

29. Humar B, H Müller and R Scott. (2001). Cell cycle dependent DNA break increase in ataxia telangiectasia lymphoblasts after radiation exposure. Mol Pathol 347-350. 
30. Dominici M, K Le Blanc, I Mueller, I Slaper-Cortenbach, F Marini, D Krause, R Deans, A Keating, D Prockop and E Horwitz. (2006). Minimal criteria for defining multipotent mesenchymal stromal cells. The International Society for Cellular Therapy position statement. Cytotherapy 8:315-317.

31. Conforti A, S Biagini, F Del Bufalo, P Sirleto, A Angioni, N Starc, G Li Pira, F Moretta, A Proia, et al. (2013). Biological, functional and genetic characterization of bone marrowderived mesenchymal stromal cells from pediatric patients affected by acute lymphoblastic leukemia. PLoS One 8:e76989.

32. Vicente López Á, MN Vázquez García, GJ Melen, A Entrena Martínez, I Cubillo Moreno, J García-Castro, MR Orellana and AGZ González. (2014). Mesenchymal stromal cells derived from the bone marrow of acute lymphoblastic leukemia patients show altered BMP4 production: correlations with the course of disease. PLoS One 9:e84496.

33. Pontikoglou C, MC Kastrinaki, M Klaus, C Kalpadakis, $\mathrm{P}$ Katonis, K Alpantaki, GA Pangalis and HA Papadaki. (2013). Study of the quantitative, functional, cytogenetic, and immunoregulatory properties of bone marrow mesenchymal stem cells in patients with B-cell chronic lymphocytic leukemia. Stem Cells Dev 22:1329-1341.

34. Janel A, F Dubois-Galopin, C Bourgne, J Berger, K Tarte, N Boiret-Dupré, S Boisgard, $\mathrm{P}$ Verrelle, P Déchelotte, O Tournilhac and MG Berger. (2014). The chronic lymphocytic leukemia clone disrupts the bone marrow microenvironment. Stem Cells Dev 23:2972-2982.

35. Aanei CM, P Flandrin, FZ Eloae, E Carasevici, D Guyotat, E Wattel and L Campos. (2012). Intrinsic growth deficiencies of mesenchymal stromal cells in myelodysplastic syndromes. Stem Cells Dev 21:1604-1615.

36. Pavlaki K, CG Pontikoglou, A Demetriadou, AK Batsali, A Damianaki, E Simantirakis, M Kontakis, A Galanopoulos, I Kotsianidis, M-C Kastrinaki and HA Papadaki. (2014). Impaired proliferative potential of bone marrow mesenchymal stromal cells in patients with myelodysplastic syndromes is associated with abnormal WNT signaling pathway. Stem Cells Dev 23:1568-1581.

37. Aoyagi M, S Furusawa, K Waga, S Tsunogake and $H$ Shishido. (1994). Suppression of normal hematopoiesis in acute leukemia: effect of leukemic cells on bone marrow stromal cells and hematopoietic progenitor cells. Intern Med 33:288-295.

38. Frisch BJ, JM Ashton, L Xing, MW Becker, CT Jordan and LM Calvi. (2012). Functional inhibition of osteoblastic cells in an in vivo mouse model of myeloid leukemia. Blood 119:540-550.

39. Bowers M, B Zhang, Y Ho, P Agarwal, C-C Chen and R Bhatia. (2015). Osteoblast ablation reduces normal longterm hematopoietic stem cell self-renewal but accelerates leukemia development. Blood 125:2678-2688.

40. Dvořáková M, V Karafiát, P Pajer, E Kluzáková, K Jarkovská, S Peková, L Krutílková, M Dvořák, M Dvorakova, et al. (2013). DNA released by leukemic cells contributes to the disruption of the bone marrow microenvironment. Oncogene 32:5201-5209.

41. Ho JH, YF Chen, WH Ma, TC Tseng, MH Chen and OK Lee. (2011). Cell contact accelerates replicative senescence of human mesenchymal stem cells independent of telomere shortening and p53 activation: roles of Ras and oxidative stress. Cell Transpl 20:1209-1220.

42. Tripodo C, A Di Bernardo, MP Ternullo, C Guarnotta, R Porcasi, S Ingrao, U Gianelli, E Boveri, E Iannitto, G Franco and AM Florena. (2009). CD146(+) bone marrow osteoprogenitors increase in the advanced stages of primary myelofibrosis. Haematologica 94:127-130.

43. Basak P, S Chatterjee, P Das, M Das, JA Pereira, RK Dutta, M Chaklader, S Chaudhuri and S Law. (2010). Leukemic stromal hematopoietic microenvironment negatively regulates the normal hematopoiesis in mouse model of leukemia. Chin J Cancer 29:969-979.

44. Sacchetti B, A Funari, S Michienzi, S Di Cesare, S Piersanti, I Saggio, E Tagliafico, S Ferrari, PG Robey, et al. (2007). Self-renewing osteoprogenitors in bone marrow sinusoids can organize a hematopoietic microenvironment. Cell 131:324-336.

45. Tormin A, O Li, JC Brune, S Walsh, B Schutz, M Ehinger, N Ditzel, M Kassem and S Scheding. (2011). CD146 expression on primary nonhematopoietic bone marrow stem cells is correlated with in situ localization. Blood 117: 5067-5077.

46. Kale S. (2004). Microarray analysis of in vitro pericyte differentiation reveals an angiogenic program of gene expression. FASEB J 19:270-271.

47. Fei C, Y Zhao, S Gu, J Guo, X Zhang, X Li and C Chang. (2014). Impaired osteogenic differentiation of mesenchymal stem cells derived from bone marrow of patients with lower-risk myelodysplastic syndromes. Tumour Biol 35:4307-4316.

48. Maijenburg MW, M Kleijer, K Vermeul, EPJ Mul, FPJ van Alphen, CE van der Schoot and C Voermans. (2012). The composition of the mesenchymal stromal cell compartment in human bone marrow changes during development and aging. Haematologica 97:179-183.

49. Reedijk M, S Odorcic, L Chang, H Zhang, N Miller, DR McCready, G Lockwood and E Sean. (2005). High-level coexpression of JAG1 and NOTCH1 is observed in human breast cancer and is associated with poor overall survival. Cancer Res 65:8530-8537.

50. Kode A, JS Manavalan, I Mosialou, G Bhagat, CV Rathinam, N Luo, H Khiabanian, A Lee, V V Murty, et al. (2014). Leukaemogenesis induced by an activating $\beta$ catenin mutation in osteoblasts. Nature 506:240-244.

51. Takam Kamga P, G Bassi, A Cassaro, M Midolo, M Di Trapani, A Gatti, R Carusone, F Resci, O Perbellini, et al. (2016). Notch signalling drives bone marrow stromal cellmediated chemoresistance in acute myeloid leukemia. Oncotarget 7:21713-21727.

52. Santamaria C, S Muntion, B Roson, B Blanco, O LopezVillar, S Carrancio, FM Sanchez-Guijo, M Diez-Campelo, S Alvarez-Fernandez, et al. (2012). Impaired expression of DICER, DROSHA, SBDS and some microRNAs in mesenchymal stromal cells from myelodysplastic syndrome patients. Haematologica 97:1218-1224.

53. Zhao Y, D Wu, C Fei, J Guo, S Gu, Y Zhu, F Xu, Z Zhang, L Wu, X Li and C Chang. (2014). Down-regulation of Dicer1 promotes cellular senescence and decreases the differentiation and stem cell-supporting capacities of mesenchymal stromal cells in patients with myelodysplastic syndrome. Haematologica 100:194-204.

54. Lee JY, KR Yu, HS Kim, I Kang, JJ Kim, BC Lee, SW Choi, JH Shin, Y Seo and KS Kang. (2016). BMI1 inhibits senescence and enhances the immunomodulatory properties of human mesenchymal stem cells via the direct suppression of MKP-1/DUSP1. Aging (Albany NY) 8:1670-1689.

55. Sparrow RL, E O'Flaherty, TM Blanksby, J Szer and MB Van Der Weyden. (1997). Perturbation in the ability of bone marrow stroma from patients with acute myeloid 
leukemia but not chronic myeloid leukemia to support normal early hematopoietic progenitor cells. Leuk Res 21:29-36.

56. Boyd AL, CJ V. Campbell, CI Hopkins, A Fiebig-Comyn, J Russell, J Ulemek, R Foley, B Leber, A Xenocostas, et al. (2014). Niche displacement of human leukemic stem cells uniquely allows their competitive replacement with healthy HSPCs. J Exp Med 211:1925-1935.

57. Arnulf B, S Lecourt, J Soulier, B Ternaux, MN Lacassagne, A Crinquette, J Dessoly, AK Sciaini, M Benbunan, et al. (2007). Phenotypic and functional characterization of bone marrow mesenchymal stem cells derived from patients with multiple myeloma. Leukemia 21:158-163.

58. Tennant GB, V Walsh, LN Truran, P Edwards, KI Mills and AK Burnett. (2000). Abnormalities of adherent layers grown from bone marrow of patients with myelodysplasia. Br J Haematol 111:853-862.

59. Jacamo R, Y Chen, Z Wang, W Ma, M Zhang, EL Spaeth, Y Wang, VL Battula, PY Mak, et al. (2014). Reciprocal leukemia-stroma VCAM-1/VLA-4-dependent activation of NF- k B mediates chemoresistance. Blood 123:2691-2702.

60. Ramasamy R, EW Lam, I Soeiro, V Tisato, D Bonnet and F Dazzi. (2007). Mesenchymal stem cells inhibit proliferation and apoptosis of tumor cells: impact on in vivo tumor growth. Leukemia 21:304-310.

61. Zambetti NA, Z Ping, S Chen, KJG Kenswil, MA Mylona, MA Sanders, RM Hoogenboezem, EMJ Bindels, MN Adisty, et al. (2016). Mesenchymal inflammation drives genotoxic stress in hematopoietic stem cells and predicts disease evolution in human pre-leukemia. Cell Stem Cell 19:613-627.

Address correspondence to: Jorge Domenech, MD, PhD Service d'Hématologie Biologique CHRU de Tours and CNRS UMR 7292 2 Boulevard Tonnellé Tours Cedex 9, 37044 France

E-mail: jorge.domenech@univ-tours.fr 


\section{Supplementary Data}

\section{Supplementary Methods}

\section{BM-derived MSC expansion and clonogenic capacity}

BM cells were obtained by iliac crest or sternal aspiration and collected in tubes containing preservative-free sodium heparin. Cells were centrifuged, seeded in flasks at a density of $5 \times 10^{4}$ per $\mathrm{cm}^{2}$ in $\alpha$ MEM culture medium (Gibco, Carlsbad, CA) supplemented with $10 \%$ fetal bovine serum (FBS) (Thermo Scientific, Waltham, MA), $20 \mu \mathrm{mol} / \mathrm{L}$ L-glutamine (Gibco), $100 \mathrm{U} / \mathrm{mL}$ penicillin $\mathrm{G}$ (Gibco), $0.1 \mathrm{mg} / \mathrm{mL}$ streptomycin (Gibco), $25 \mu \mathrm{g} / \mathrm{mL}$ Fungizone (Bristol-Myers Squibb, New York, NY), 1 ng/mL FGF2 (R\&D, Minneapolis, MN). Cells were grown at $37^{\circ} \mathrm{C}$ in humidified air with $5 \% \mathrm{CO}_{2}$. The expansion medium was completely renewed every 3-4 days. When adherent cells reached $90 \%$ confluence, they were detached by enzymatic treatment with $0.05 \%$ trypsin/EDTA solution (Invitrogen, Carlsbad, CA) at $37^{\circ} \mathrm{C}$ for 5 min and seeded at $1 \times 10^{3}$ per $\mathrm{cm}^{2}$ at each passage. Cells were amplified up to passage (P) 2 or 3 before testing. Each assay was carried out using MSC samples at the same passage number. To measure MSC proliferation capacity, the population doubling time (PDT), which represents the mean duration of one cell division, was estimated for a given passage as $t / n$, where $t$ is the culture duration (in days) and $n$ the number of population doublings, calculated by using the formula $n=\left(\log \mathrm{N}_{\mathrm{h}}-\log \mathrm{N}_{\mathrm{i}}\right) / \log 2\left(\right.$ where $\mathrm{N}_{\mathrm{h}}$ was the number of cells counted at the end of the passage and $\mathrm{N}_{i}$ the number of cells initially plated). Cells were counted after excluding dead cells by Trypan blue dye (Sigma Aldrich, St. Louis, MO). MSC proliferative capacity was also assessed using the CFSE assay (eBioscience, San Diego, CA), in which detached MSCs were stained with $1 \mu \mathrm{M}$ CFSE and seeded at $6.10^{3}$ cells per $\mathrm{cm}^{2}$. The decrease of CFSE mean fluorescence intensity (MFI) measured after 24 and 96 hours of staining by flow cytometry $\left(\right.$ Gallios $^{\circledR}$, Beckman-Coulter, Indianapolis, IN) reflects the number of mitoses during 72 hours. 
MSC clonogenic capacity was assessed by colony forming unit-fibroblast (CFU-F) assay. Detached adherent cells were seeded at $10-40 / \mathrm{cm}^{2}$ in T-25 flasks. At day 10, cell clusters containing more than 50 cells were scored as CFU-F colonies using an inverted microscope.

\section{BM-derived MSC differentiation potential}

Osteogenic lineage induction. At 50\% confluence, cells were cultured for 14 days in DMEMHG (High Glucose $4.5 \mathrm{~g} / \mathrm{L}$; Gibco, Carlsbad, CA) containing 2\% FBS, $0.1 \mu \mathrm{M}$ dexamethasone (Sigma-Aldrich, St. Louis, MO), 2 mM $\beta$-glycerolphosphate (Sigma-Aldrich) and $100 \mu \mathrm{M}$ ascorbate-2-phosphate (Sigma-Aldrich). Medium was changed every 3-4 days. After 2 weeks of induction, the presence of calcium deposition was revealed by Alizarin Red staining.

Adipogenic lineage induction. The adipogenic lineage induction medium consisted of DMEM-LG (Low Glucose 1g/L; Gibco) supplemented with 20\% FBS, $1 \mu \mathrm{M} / \mathrm{L}$ dexamethasone (Sigma-Aldrich), $0.5 \mathrm{mmol} / \mathrm{L}$ isobutylmethylxanthine (IBMX; SigmaAldrich) and $60 \mu \mathrm{mol} / \mathrm{L}$ indomethacin (Sigma-Aldrich). Medium was changed every 3-4 days until day 14. Adipogenic differentiation was evaluated by Nile Red staining (Sigma-Aldrich) of neutral lipid vacuoles that were observed using a Leica DMR fluorescence microscope (Leica Microsystems, Buffalo Grove, IL).

Chondrogenic lineage induction. Chondrogenic differentiation was obtained by incubating cell micropellets $\left(3 \times 10^{5}\right.$ cells per pellet) in tubes at $37^{\circ} \mathrm{C}$ for 21 days in $500 \mu \mathrm{L}$ chondrogenic medium consisting of DMEM-HG with $0.1 \mu \mathrm{M}$ dexamethasone (Sigma-Aldrich), $1 \mathrm{mM}$ sodium pyruvate, $170 \mu \mathrm{M}$ ascorbic acid-2-phosphate (Sigma-Aldrich), $350 \mu \mathrm{M}$ proline (Sigma-Aldrich), 1X insulin-transferrin-selenium (ITS, Cambrex, East Rutherford, NJ) and 10 ng/mL TGF- $\beta 1$ (Eurobio/Abcys, Les Ulis, France). Medium was changed every 3-4 days. Chondrogenic differentiation was evaluated after 21 days of induction. The presence of glycosaminoglycans in cell pellets was revealed by Toluidine-blue staining and immunofluorescence labeling with an anti-collagen type II antibody. Briefly, pellets were 
fixed in $4 \%$ formaldehyde for $48 \mathrm{hr}$ and embedded in paraffin. Four- $\mu \mathrm{m}$ thick sections were rehydrated in successive baths of xylene, $100 \%, 90 \%$ and $70 \%$ ethanol and then water. For Toluidine-blue staining, cells were incubated in a $1 \%$ Toluidine-blue (Sigma-Aldrich) (v/v) solution in $70 \%$ ethanol for $10 \mathrm{~min}$. For collagen type II labeling, cells were incubated first in permeabilization buffer (1\% BSA, 1\% FBS and 0.3\% Triton X-100 in PBS) for 1 hour and then with an anti-human collagen type II rabbit polyclonal antibody (Millipore) at $4^{\circ} \mathrm{C}$ overnight. After incubation with an Alexa-488-conjugated goat anti-rabbit secondary antibody (Invitrogen, Carlsbad, CA) for 1 hour, slides were mounted with Vectashield+DAPI ${ }^{\circledR}$ (Eurobio/Abcys) before examination with a fluorescence microscopy.

\section{MSC cell cycle analysis}

The percentage of detached MSCs in the G0, G1 or S/G2/M phase of the cell cycle was determined by flow cytometry (BD Accuri $6^{\circledR}{ }^{\circledR}$, BD Biosciences) after staining with 7-AAD (Sigma Aldrich, St. Louis, MO) and an anti-human KI67-Alexa Fluor 488-conjugated antibody (BD Biosciences, Franklin Lakes, NJ), as previously described [27]. Additionally, expression of the cell cycle proteins cyclin D1, p21, p27 and p53 in MSCs was investigated by western blotting. MSCs were harvested at $90 \%$ confluence by incubation with trypsin/EDTA. Cell pellets were resuspended in lysis buffer [150 mM NaCl (Sigma-Aldrich), 50 mM Tris-HCl pH 6.8 (Bio-Rad, Hercules, CA), 10\% Glycerol (Sigma-Aldrich), 1\% Igepal CA-630 (NP-40, Sigma-Aldrich), 0.01\% sodium azide (Sigma-Aldrich), 1x Halt Phosphatase Inhibitor Cocktail (Thermo Scientific), 1x Protease Inhibitor Cocktail (Roche) and PMSF]. A total of $1.5 \times 10^{5}$ cells were separated by SDS-PAGE and electrophoretically transferred onto nitrocellulose membranes (GE Healthcare, Fairfield, CT). Membranes were blocked in 5\% dried milk and then incubated with anti-human actin (Goat, Santa Cruz Biotechnology, Santa Cruz, CA) or -GAPDH (clone D16H11, rabbit IgG, Cell Signaling Technology, Danvers, MA) antibodies as loading controls, or with primary rabbit anti-human antibodies from Cell Signaling against $27^{\mathrm{Kip} 1}$ (clone D69C12), p21 ${ }^{\mathrm{Waf} 1 / \mathrm{Cip} 1}$ (clone 12D1), p53, cyclin D1 (clone 
DCS6, mouse IgG2) and then with horseradish peroxidase (HRP) conjugated anti-goat (Santa Cruz Biotechnology), anti-rabbit (Cell Signaling) or anti-mouse (GE Healthcare) secondary antibodies. After chemiluminescence detection using the ECL Western blotting detection kit (GE Healthcare), bands were quantified using the Image ${ }^{\circledR}$ software.

\section{MSC damage evaluation}

MSC apoptosis. Cell apoptosis rate was assessed by flow cytometry using the Annexin VFITC/7-AAD Kit (Beckman-Coulter, Indianapolis, IN) [28] to determine the percentages of live $\left(7-\mathrm{AAD}^{\text {neg }} / \mathrm{Annexin} \mathrm{V}^{\text {neg }}\right)$, early apoptotic $\left(7-\mathrm{AAD}^{\text {neg }} /\right.$ Annexin $\mathrm{V}^{\text {pos }}$ ) and of secondary necrotic (7-AAD ${ }^{\text {pos }} /$ Annexin $\mathrm{V}^{\text {pos }}$ ) cells. Late apoptosis was assessed in ethanol-permeabilized cells after 7-AAD staining to detect hypoploid nuclei (sub-G1 peak).

Cell senescence. Senescence rates were assessed on adherent layers of MSC at $70 \%$ confluence, using the Senescence Cells Histochemical Staining Kit (Sigma Aldrich) that is based on the specific histochemical detection of $\beta$-galactosidase enzymatic activity at $\mathrm{pH} 6$. After 24 hours of staining, the percentage of positive cells (in blue) was evaluated under an inverted microscope by counting at least 200 cells in random fields.

MSC telomere length. DNA from MSC was extracted with the Genomic DNA from Tissue kit (Macherey-Nagel Dueren, Germany) according to the manufacturer's recommendations. MSC telomere length was measured by Southern blot analysis of terminal restriction fragments as previously described [29].

Reactive oxygen species production. The amount of intracellular reactive oxygen species (ROS) was evaluated in trypsin/EDTA-harvested MSCs by CM-H2DCFDA staining (Molecular Probes, Carlsbad, CA). Cells were incubated with $10 \mu \mathrm{m} C \mathrm{CM}_{2} \mathrm{H}_{2} \mathrm{DCFDA}$ in XVIVO $10^{\circledR}$ medium without gentamicin and phenol red (Lonza, Basel, Switzerland) at $37^{\circ} \mathrm{C}$ and in the dark for $10 \mathrm{~min}$. The emitted fluorescence was detected with a Gallios ${ }^{\circledR}$ flow cytometer. 
DNA double-strand break formation. Presence of DNA double-strand breaks was assessed in detached MSCs by staining with a FITC-conjugated antibody against phospho-Histone H2AX (Ser139) $(\gamma \mathrm{H} 2 \mathrm{AX})$ (clone JBW301, IgG1, EMD Millipore, Billerica, MA) diluted in 1\% FBS/0.25\% Triton X-100/PBS after ethanol permeabilization. $\gamma \mathrm{H} 2 \mathrm{AX}$ MFI was measured using a BD Accuri $\mathrm{C6}^{\circledR}$ flow cytometer.

\section{MSC gene and protein expression related to niche function}

Reverse transcriptase-quantitative polymerase chain reaction (RT-qPCR) analysis. We evaluated 93 genes encoding proteins related to the hematopoietic or tumor niche (cell adhesion, extracellular matrix, cytoskeleton, growth factors, cytokines and chemokines), mesenchymal differentiation, development/embryogenesis and antioxidant enzymes (Supplementary Table S2). TaqMan low density arrays (TLDA) (Micro Fluidic Cards, Applied Biosystems, Carlsbad, CA) were used in a single-step RT-qPCR process. Total cellular RNA was extracted from harvested cells using TRIzol reagent (Invitrogen) in accordance with the manufacturer's instructions. First strand cDNA was synthesized from 3 $\mu \mathrm{g}$ of total RNA using the High-Capacity cDNA Archive Kit (Applied Biosystems). PCR reactions were then performed on Micro Fluidic Cards using the ABI PRISM 7900HT Sequence Detection System (Applied Biosystems). Probes were labeled with the fluorescent reporter dye 6-carboxyfluorescein (FAM, Applera corp.) on the 5'-end and with a nonfluorescent quencher on the 3'-end. $100 \mathrm{ng}$ of cDNA combined with $1 \mathrm{X}$ TaqMan Universal Master Mix (Applied Biosystems) were loaded in each well. Thermal cycling conditions were as follows: $50^{\circ} \mathrm{C}$ for $2 \mathrm{~min}$ and $94.5^{\circ} \mathrm{C}$ for $10 \mathrm{~min}$ followed by 40 cycles at $97^{\circ} \mathrm{C}$ for $30 \mathrm{~s}$ and $59.7^{\circ} \mathrm{C}$ for $1 \mathrm{~min}$. Data were collected with instrument spectral compensations by the Applied Biosystems SDS 2.2.1 software and analyzed using the cycle threshold $(\mathrm{Ct})$ relative quantification method. Genes with $\mathrm{Ct}$ values higher than 40 were considered as not amplified. The amount of the target was normalized to a computed endogenous control (aggregated median of the $B 2 M$ and $E I F 2 B 1$ expression values $)\left(\Delta \mathrm{Ct}=\mathrm{Ct}_{\text {target }}-\mathrm{Ct}_{\text {endogenous control }}\right)$ that 
allowed calculating the $2^{-\Delta \mathrm{Ct}}$ value, which reflects the ratio of each target gene expression relative to that of control.

Cytokine concentration in MSC supernatants. Cytokine levels were measured in supernatants of sub-confluent MSCs at P2 by ELISA using the Quantikine Human Immunoassays (R\&D Systems, Minneapolis, MN) for stromal cell-derived factor-1 alpha (SDF-1 $\alpha$ ), angiopoietin-1 (ANG-1), thrombopoietin (TPO) and stem cell factor (SCF), according to the manufacturer's recommendations.

Immunophenotype analysis. Membrane antigen expression was assessed by flow cytometry after direct (for CD45, CD14, CD34, CD309, CD73, CD90, CD105, CD49e, CD146) or indirect (for CD106) staining of trypsin/EDTA-detached sub-confluent MSCs at P2. Cell suspensions were incubated at $4^{\circ} \mathrm{C}$ in the dark for $1 \mathrm{~h}$ with the following mouse monoclonal antibodies (mAbs) from BD Biosciences (or otherwise indicated) diluted in PBS: APCconjugated anti-CD45 (clone J.33, IgG1, Beckman-Coulter), R-PE-conjugated anti-CD14 (clone TUK4, IgG2, Dako, Carpinteria, CA), PE-conjugated anti-CD34 (clone 8G12, IgG1), PE-conjugated anti-CD31 (clone WM59, IgG1), PE-conjugated anti-CD309 (clone 89106, IgG1), PE-conjugated anti-CD73 (clone AD2, IgG1), PE-conjugated anti-CD90 (clone 5E10, IgG1), R-PE-conjugated anti-CD105 (clone SN6, IgG1, Invitrogen), FITC-conjugated antiCD49e (clone SAM1, IgG2, Beckman-Coulter), PE-conjugated anti-CD146 (clone P1H12, IgG1) and APC-, PE- or FITC- conjugated isotypic controls. For indirect staining, cell suspensions were successively incubated with an anti-human CD106 monoclonal antibody (mAb) (clone 1.G11B1, IgG1, Southern Biotech, Birmingham, AL) at $4^{\circ} \mathrm{C}$ for $30 \mathrm{~min}$, then with a biotinylated anti-mouse IgG mAb (Eurobio/Abcys, Les Ulis, France) at $4^{\circ} \mathrm{C}$ for $30 \mathrm{~min}$ and finally with PE-streptavidin (BD Biosciences) at $4{ }^{\circ} \mathrm{C}$ in the dark for 15 min. Cells were fixed with CellFix ${ }^{\circledR}$ (BD Biosciences) and analyzed using a FACSCanto II $^{\circledR}$ flow cytometer (BD Biosciences) with the FlowJo ${ }^{\circledR}$ software (TreeStar, Ashland, OR) or a Gallios ${ }^{\circledR}$ flow cytometer with the Kaluza ${ }^{\circledR}$ software (Beckman-Coulter). Antigen expression intensity was 
evaluated as signal/noise ratios by calculating the ratio of the geometric median fluorescence intensity of a specific mAb to that of the isotypic control antibody.

Immunofluorescence. The MSC expression of fibronectin, ASMA and nestin was observed by immunofluorescence staining. MSCs were cultured on Lab-Tek ${ }^{\circledR}$ chamber slides (Nunc, VWR International). When $80 \%$ confluent, cells were fixed with $4 \%$ formaldehyde and permeabilized with PBS containing $0.5 \%$ Tween 20 and $1 \%$ BSA for 1 hour. Cells were incubated at $4{ }^{\circ} \mathrm{C}$ with anti-human alpha-smooth muscle actin (ASMA; clone 14A, IgG1, Sigma-Aldrich), -fibronectin (Clone NCL-FIB, IgG1, Leica Microsystems) and -nestin (clone 3K1, IgG1, Stemgent, Cambridge, MA) monoclonal antibodies overnight, followed by Alexa488-conjugated goat anti-mouse antibodies (Invitrogen) for 1 hour. Slides were mounted with Vectashield containing DAPI before analysis with a Leica DMR fluorescence microscope (Leica Microsystems, Buffalo Grove, IL).

\section{MSC hematopoietic supporting activity assessed by Dexter-type long-term cultures}

Confluent adherent layers of cultured MSCs in T-25 flasks were irradiated (10 Gy) and recharged with $1.4 \times 10^{4} / \mathrm{mL}$ CD34 $4^{\text {pos }}$ cells in $5 \mathrm{~mL}$ Myelocult ${ }^{\circledR}$ medium (H5100, StemCell Technologies, Vancouver, Canada) supplemented with $10^{-6} \mathrm{M}$ hydrocortisone (SigmaAldrich). CD34 ${ }^{\text {pos }}$ cells were obtained by immunomagnetic selection (CD34 MicroBead ${ }^{\circledR}$ Kit, MACS, Miltenyi Biotec, Auburn, CA) of cells collected by peripheral blood apheresis in patients after G-CSF-induced mobilization for autologous stem cell transplantation (CentreAtlantic Regional Blood Bank, Bretonneau Hospital, Tours, France). Cultures were then incubated at $37{ }^{\circ} \mathrm{C}$ and $5 \% \mathrm{CO}_{2}$ for five weeks. Half of the supernatant was harvested weekly and cells plated for hematopoietic progenitor cell (HPC) enumeration by clonogenic assay (Methocult $^{\circledR}, \mathrm{H} 84434$, StemCell Technologies). At the end of the culture, HPCs were also quantified in adherent layers. After 14 days, colony-forming unit-macrophage (CFU-M), colony-forming unit-granulocyte/macrophage (CFU-GM) and burst-forming unit-erythroid (BFU-E) progenitors were enumerated from the different colonies observed. 


\section{MSC leukemic cell supporting activity}

MSC influence on leukemic cell behavior was evaluated by co-culturing in T-25 flasks MSCs from patients with AML-M0/1 (L-MSCs) or from controls (N-MSCs) with KG1a cells (European Collection of Cell Cultures, Salisbury, UK) for three days in $5 \mathrm{~mL}$ of expansion medium without FGF2 (co-culture medium) at $37^{\circ} \mathrm{C}$ in $5 \% \mathrm{CO}_{2}(\mathrm{n}=6 /$ each group). Similar cocultures were performed with primary blast cells (AML-M0/1) in heterologous or autologous settings for two days ( $\mathrm{n}=4$ for each group and each setting). Controls were KG1a cells $(\mathrm{n}=3)$ and primary blast cells $(n=4)$ grown without MSCs. After 2-3 days, supernatants of cocultures (and from cultures without MSCs) were collected and adherent cells were detached with EDTA/Trypsin. Adherent and non-adherent cells were separately counted and studied. For each experiment, one L-MSC co-culture was matched with one N-MSC co-culture and both were compared to the MSC-free condition. Leukemic cells (KG1a cells and primary blast cells) cultured in the presence or not of MSCs were labeled with an APC-conjugated anti-CD45 antibody and analyzed by flow cytometry. Then, the adherence rate, the number of live leukemic (after staining with $5 \mathrm{ng} / \mu \mathrm{L}$ of 7 -AAD) and the number of apoptotic (after costaining with the Annexin V-FITC/7-AAD Kit, Beckman-Coulter) [28] cells were measured in the $\mathrm{CD} 45^{\text {pos }}$ cell fraction. The cell cycle distribution of $\mathrm{CD} 45^{\text {pos }}$ cells stained with 7AAD/Ki-67 [27] was also analyzed. Finally, the presence of DNA double-strand breaks in primary blast cells was assessed by $\gamma \mathrm{H} 2 \mathrm{AX}$ staining, as described above, followed by incubation with the anti-CD45 antibody. 


\section{Supplementary Tables}

Table S1. Clinical data of the patients with AML $(\mathrm{n}=19) . *$ MSCs from these patients were used to test MSC hematopoietic supportive function ( $a, b, c, d$ ). Abbreviations: $M / F$, male/female; FAB type, French-American-British type; G/L, giga per liter; N/A, not available; DP, disease progression; $\mathrm{CR}$, complete remission

\begin{tabular}{|c|c|c|c|c|c|c|c|c|c|}
\hline $\begin{array}{l}\text { Patient } \\
\text { number }\end{array}$ & $\begin{array}{l}\text { Age at } \\
\text { diagnosis } \\
\text { (years) }\end{array}$ & $\begin{array}{c}\text { Sex } \\
(\mathbf{M} / \mathbf{F})\end{array}$ & FAB type & $\begin{array}{c}\text { Leucocyte } \\
\text { count at } \\
\text { diagnosis } \\
(\mathbf{G} / \mathrm{L})\end{array}$ & $\begin{array}{c}\text { Bone } \\
\text { marrow } \\
\text { myelogram } \\
\text { cellularity } \\
(+ \text { to }++++)\end{array}$ & $\begin{array}{l}\text { blast cells } \\
\text { in bone } \\
\text { marrow at } \\
\text { diagnosis } \\
(\%) \\
\end{array}$ & $\begin{array}{c}\text { Cytogenetic } \\
\text { profile }\end{array}$ & $\begin{array}{l}\text { Cytogenetic } \\
\text { prognostic } \\
\text { value }\end{array}$ & $\begin{array}{c}\text { Disease } \\
\text { status at } \\
\text { the end } \\
\text { of the } \\
\text { study }\end{array}$ \\
\hline 2393 & 72 & M & AML-M0 & 7 & +++ & 43 & All other & Intermediate & DP \\
\hline 2576 (a)* & 48 & $\mathrm{~F}$ & AML-M0 & 8 & +++ & 72 & $\begin{array}{c}\text { Abnormal } \\
3 \mathrm{q}\end{array}$ & Unfavorable & DP \\
\hline 3060 (b)* & 12 & M & AML-M0 & 70 & ++++ & 96 & All other & Intermediate & CR \\
\hline 3456 (d)* & 70 & M & AML-M0 & 73 & ++++ & 87 & All other & Intermediate & DP \\
\hline 4393 & 72 & M & AML-M0 & 85 & +++ & 77 & All other & Intermediate & DP \\
\hline 3141 & 80 & M & AML-M1 & 224 & ++++ & 88 & N/A & N/A & DP \\
\hline 3244 & 13 & M & AML-M1 & 137 & ++++ & 98 & Complex & Unfavorable & DP \\
\hline $3436(c)^{*}$ & 33 & M & AML-M1 & 40 & ++++ & 88 & All other & Intermediate & CR \\
\hline 3815 & 37 & M & AML-M1 & 23 & ++++ & 84 & Normal & Intermediate & DP \\
\hline 3968 & 59 & $\mathrm{~F}$ & AML-M1 & 274 & ++++ & 96 & Normal & Intermediate & CR \\
\hline 1911 & 32 & M & AML-M3 & 1 & +++ & 95 & $\mathrm{t}(15 ; 17)$ & Favorable & CR \\
\hline 2324 & 41 & M & AML-M3 & 11 & ++++ & 89 & $\mathrm{t}(15 ; 17)$ & Favorable & $\mathrm{CR}$ \\
\hline 3221 & 66 & M & AML-M3 & 19 & ++++ & 83 & $\mathrm{t}(15 ; 17)$ & Favorable & DP \\
\hline 2448 & 80 & $\mathrm{~F}$ & AML-M4 & 57 & +++ & 33 & Normal & Intermediate & DP \\
\hline 3015 & 32 & $\mathrm{~F}$ & AML-M4 & 116 & ++++ & 87 & All other & Intermediate & $\mathrm{CR}$ \\
\hline 3083 & 50 & $\mathrm{~F}$ & AML-M4 & 8 & +++ & 54 & -7 & Unfavorable & $\mathrm{CR}$ \\
\hline 3051 & 48 & $\mathrm{~F}$ & AML-M5 & 34 & ++++ & 70 & All other & Intermediate & DP \\
\hline 3030 & 17 & M & AML-M5 & 144 & ++++ & 96 & All other & Intermediate & $\mathrm{CR}$ \\
\hline 3075 & 70 & $\mathrm{~F}$ & AML-M5 & 63 & ++++ & 82 & All other & Intermediate & DP \\
\hline
\end{tabular}

Table S2 List of the 95 genes tested by using TaqMan Array Microfluidic Cards and RTqPCR and their TaqMan assay ID. 


\begin{tabular}{|c|c|c|}
\hline Acronym & Gene name & $\begin{array}{c}\text { Assay on } \\
\text { demand ID }\end{array}$ \\
\hline $\begin{aligned} & \text { ACTA2 } \\
(= & \operatorname{alphaSMA})\end{aligned}$ & actin, alpha 2 , smooth muscle, aorta & Hs00426835_g1* \\
\hline$A L P L$ & $\begin{array}{c}\text { alkaline phosphatase, } \\
\text { liver/bone/kidney }\end{array}$ & Hs01029144_m1* \\
\hline ANGPT1 & angiopoietin 1 & $\mathrm{Hs} 00375822 \mathrm{~m} 1 *$ \\
\hline$B 2 M$ & beta-2-microglobulin & Hs99999907 m1 \\
\hline BGLAP & $\begin{array}{c}\text { gamma-carboxyglutamic acid protein, } \\
\text { bone/osteocalcin }\end{array}$ & Hs01587814_g1* \\
\hline BMI1 & $\begin{array}{l}\text { Leukemia viral BMI-1 oncogene, } \\
\text { mouse, homolog of }\end{array}$ & Hs00180411_m1* \\
\hline BMP1 & bone morphogenetic protein 1 & Hs00986789_m1* \\
\hline BMP2 & bone morphogenetic protein 2 & Hs00154192 m1* \\
\hline BMP4 & bone morphogenetic protein 4 & Hs00181626_m1 \\
\hline BST1 & bone marrow stromal cell antigen 1 & Hs00174709_m1* \\
\hline BST2 & bone marrow stromal cell antigen 2 & Hs00171632_m1* \\
\hline$C A T$ & catalase & Hs00156308_m1* \\
\hline CCL19 & chemokine (C-C motif) ligand 19 & Hs00171149_m1* \\
\hline CCL2 & chemokine (C-C motif) ligand 2 & Hs00234140_m1* \\
\hline CD133/PROM1 & prominin 1 & Hs01009250_m1* \\
\hline $\mathrm{CDH} 2$ & $\begin{array}{c}\text { cadherin 2, type } 1, \mathrm{~N} \text {-cadherin } \\
\text { (neuronal) }\end{array}$ & Hs00983056_m1* \\
\hline$C L U$ & clusterin & Hs00156548_m1* \\
\hline COL10A1 & $\begin{array}{c}\text { collagen, type } \mathrm{X} \text {, alpha } 1 \text { (Schmid } \\
\text { metaphyseal chondrodysplasia) }\end{array}$ & Hs00166657_m1* \\
\hline COL1A1 & collagen, type I, alpha 1 & $\mathrm{Hs} 00164004 \mathrm{~m} 1 *$ \\
\hline $\operatorname{COL} 2 A 1$ & collagen, type II, alpha 1 & Hs00264051_m1* \\
\hline COL4A1 & collagen, type IV, alpha 1 & Hs00266237_m1* \\
\hline CTNNB1 & beta-catenin & Hs99999168 m1 \\
\hline $\mathrm{CXCL12}$ & $\begin{array}{c}\text { chemokine (C-X-C motif) ligand } 12 \\
(\text { stromal cell-derived factor } 1)\end{array}$ & Hs00171022_m1* \\
\hline CXCL9 & chemokine (C-X-C motif) ligand 9 & Hs00171065 m1* \\
\hline$D C N$ & decorin & Hs00754870_s1* \\
\hline $\mathrm{DHH}$ & desert hedgehog & Hs00368306_m1* \\
\hline DICER1 & $\begin{array}{c}\text { double-stranded RNA-specific } \\
\text { endoribonuclease }\end{array}$ & Hs00229023_m1* \\
\hline DNMT1 & $\begin{array}{c}\text { DNA (cytosine-5-)-methyltransferase } \\
1\end{array}$ & Hs00154749_m1* \\
\hline$E I F 2 B 1$ & $\begin{array}{c}\text { eukaryotic translation initiation factor } \\
2 \mathrm{~B} \text {, subunit } 1 \text { alpha, } 26 \mathrm{kDa}\end{array}$ & Hs00426752_m1 \\
\hline FGF7 & $\begin{array}{c}\text { fibroblast growth factor } 7 \\
\text { (keratinocyte growth factor) }\end{array}$ & Hs00384281_m1* \\
\hline FLT3LG & fms-related tyrosine kinase 3 ligand & Hs00181740_m1* \\
\hline FN1 & fibronectin & Hs01549976_m1* \\
\hline FOXO1 & forkhead box O1 & Hs01054576_m1* \\
\hline FOXO3 & forkhead box $\mathrm{O} 3$ & Hs00818121_m1 \\
\hline GDF15 & growth differentiation factor 15 & Hs00171132 m1* \\
\hline$G L R X$ & glutaredoxin (thioltransferase) & Hs00829752_g1* \\
\hline$G L R X 2$ & glutaredoxin 2 & Hs00375015_m1* \\
\hline$G L R X 3$ & glutaredoxin 3 & Hs01582641 g1* \\
\hline GLRX5 & glutaredoxin 5 & Hs00746721_s1* \\
\hline GPX1 & glutathione peroxidase 1 & Hs00829989 $\mathrm{gH}^{*}$ \\
\hline GPX2 & glutathione peroxidase 2 & Hs01591589_m1* \\
\hline GPX3 & glutathione peroxidase 3 (plasma) & Hs00173566_m1* \\
\hline GPX4 & $\begin{array}{c}\text { glutathione peroxidase } 4 \\
\text { (phospholipid hydroperoxidase) }\end{array}$ & Hs00989766_g1* \\
\hline$G P X 5$ & glutathione peroxidase 5 & Hs00559733 m1* \\
\hline GPX7 & glutathione peroxidase 7 & $\mathrm{Hs} 00210410 \mathrm{ml}$ \\
\hline GSR & glutathione reductase & Hs00167317 m1* \\
\hline$H D A C 1$ & histone deacetylase & Hs02621185_s1* \\
\hline HES1 & $\begin{array}{l}\text { hairy/enhancer of split 1, Drosophila, } \\
\text { homolog of, }\end{array}$ & Hs00172878_m1* \\
\hline
\end{tabular}

\begin{tabular}{|c|c|c|}
\hline Acronym & Gene name & $\begin{array}{c}\text { Assay on } \\
\text { demand ID }\end{array}$ \\
\hline$H G F$ & $\begin{array}{l}\text { hepatocyte growth factor (hepatopoietin } \\
\text { A; scatter factor) }\end{array}$ & Hs00300159_m1* \\
\hline IHH & indian hedgehog & Hs01081800_m1* \\
\hline ILS & interleukine8 & $\mathrm{Hs} 00174103 \mathrm{~m} 1^{*}$ \\
\hline ITGA4 & integrin, alpha 4 & $\mathrm{Hs} 00168433 \mathrm{~m} 1^{*}$ \\
\hline ITGA5 & integrin, alpha 5 & Hs01547673_m1* \\
\hline ITGA6 & integrin, alpha 6 & Hs01041011_m1* \\
\hline ITGA7 & integrin, alpha 7 & Hs00174397_m1* \\
\hline$J A G 1$ & jagged 1 (Alagille syndrome) & $\mathrm{Hs} 01070032 \mathrm{~m} 1 *$ \\
\hline$\overline{J A M 2}$ & junctional adhesion molecule 2 & Hs01022013 m1* \\
\hline KITLG & KIT ligand & Hs00241497 m1* \\
\hline$L P L$ & lipoprotein lipase & Hs00173425_m1* \\
\hline MCAM & $\begin{array}{l}\text { melanoma cell adhesion } \\
\text { molecule/MUC18/CD146 }\end{array}$ & Hs00174838_m1* \\
\hline MET & $\begin{array}{l}\text { met proto-oncogene (hepatocyte growth } \\
\text { factor receptor) }\end{array}$ & Hs01565584_m1* \\
\hline MITF & $\begin{array}{l}\text { microphthalmia-associated transcription } \\
\text { factor }\end{array}$ & Hs01117294_m1* \\
\hline MYH11 & myosin, heavy chain 11 , smooth muscle & Hs00224610_m1* \\
\hline NANOG & homeobox transcription factor NanoG & Hs02387400_g1* \\
\hline NES & nestin & Hs00707120_s1* \\
\hline$N G F R / C D 271$ & nerve growth factor receptor & Hs00609976_m1* \\
\hline NRP2 & neuropilin 2 & Hs00187290 m1* \\
\hline OCT4/POU5F1 & $\begin{array}{l}\text { POU domain, class } 5 \text {, transcription } \\
\text { factor } 1\end{array}$ & Hs00742896_s1 \\
\hline$P D P N$ & podoplanin & Hs00366766_m1* \\
\hline$P G F$ & placental growth factor & $\mathrm{Hs} 01119262 \mathrm{~m} 1^{*}$ \\
\hline PPARG & $\begin{array}{l}\text { peroxisome proliferator-activated } \\
\text { receptor gamma }\end{array}$ & Hs01115513_m1* \\
\hline PRDXI & peroxiredoxin 1 & Hs03044567 g1* \\
\hline PRDX2 & peroxiredoxin 2 & Hs03044902 g1* \\
\hline PRDX3 & peroxiredoxin 3 & Hs00428953_g1* \\
\hline PRDX4 & peroxiredoxin 4 & Hs00197394_m1* \\
\hline PRDX5 & peroxiredoxin 5 & Hs00738905_g1* \\
\hline PRDX6 & peroxiredoxin 6 & Hs00705355_s1* \\
\hline$R U N X 2$ & runt-related transcription factor 2 & Hs00231692_m1* \\
\hline SHH & sonic hedgehog & Hs00179843_m1* \\
\hline SOD1 & superoxide dismutase 1 & Hs00533490_m1* \\
\hline SOD2 & superoxide dismutase 2 , mitochondrial & Hs00167309_m1* \\
\hline SOD3 & superoxide dismutase 3 , extracellular & Hs00162090_m1* \\
\hline SOX2 & Sry-box 2 & Hs01053049_s1* \\
\hline$S P P 1$ & $\begin{array}{c}\text { secreted phosphoprotein } 1 \text { (osteopontin, } \\
\text { bone sialoprotein I, early T-lymphocyte } \\
\text { activation 1) }\end{array}$ & Hs00959010_m1* \\
\hline SULF1 & sulfatase 1 & Hs00290918_m1* \\
\hline SULF2 & sulfatase 2 & Hs01016480 m1* \\
\hline TAGLN & transgelin & Hs01038777_g1* \\
\hline TERT & telomerase reverse transcriptase & Hs00972656 m1* \\
\hline THPO & thrombopoietin & Hs01061346_m1* \\
\hline$T N F S F 13 B / B A F F$ & $\begin{array}{l}\text { tumor necrosis factor (ligand) } \\
\text { superfamily, member } 13 \mathrm{~b}\end{array}$ & Hs00198106_m1* \\
\hline$T X N$ & thioredoxin & Hs01555212_g1* \\
\hline$T X N 2$ & thioredoxin 2 & Hs00912509 g1* \\
\hline VCAM1 & vascular cell adhesion molecule 1 & $\mathrm{Hs} 01003372 \mathrm{~m} 1 *$ \\
\hline VEGFA & vascular endothelial growth factor A & $\mathrm{Hs} 00900055 \mathrm{~m} 1 *$ \\
\hline WNT3A & $\begin{array}{l}\text { wingless-type MMTV integration site } \\
\text { family, member 3A }\end{array}$ & Hs00263977_m1* \\
\hline
\end{tabular}




\section{Supplementary Figure Legends}

FIG. S1. (A): Cell cycle distribution analysis of L-MSCs $(n=6)$ and N-MSCs $(n=6)$ by flow cytometry. Cells were fixed and permeabilized with ethanol before staining with 7-AAD and an anti-KI-67 antibody. (B): Expression of cell cycle markers (cyclin D1, p21, p27 and p53) in MSC cultures was assessed by western blotting (L-MSCs; $n=5$; N-MSCs; $n=5$ ). GAPDH was used as loading control. (C): Densitometric quantification of the western blot results. The integrated density value of a specific protein band was normalized to that of GAPDH and expressed in arbitrary units. Black diamonds, individual N-MSC samples; triangles, individual L-MSC samples from patients with AML-M0/1. Horizontal bars represent the medians.

FIG. S2. (A): Assessment of DNA double-strand breaks by flow cytometry analysis of $\gamma \mathrm{H} 2 \mathrm{AX}$ staining (mean fluorescent intensity, MFI). Shown are the individual MFI values of different L-MSC $(n=6)$ and N-MSC samples $(n=6)$. $(\mathbf{B})$ : Senescence evaluated as percentage of $\beta$-galactosidase-positive cells in L-MSC $(n=16)$ and N-MSC ( $\mathrm{n}=10)$ samples. (C): Measurement of telomere length by Southern blotting of terminal restriction fragments in LMSCs ( $\mathrm{n}=5)$ and N-MSCs (n=5). (D): Intracellular ROS production was evaluated by flow cytometry after staining with the ROS detector CM- $\mathrm{H}_{2}$ DCFDA in L-MSCs $(n=6)$ and NMSCs (n=6). For symbols see legend to Fig. S1A. Horizontal bars represent the medians.

FIG. S3. Transcriptional profiles of additional genes expressed in L-MSCs $(n=12)$ and NMSCs $(n=6)$. (A): Profile of 16 genes differentially expressed $(p<0.05)$ in L-MSCs and NMSCs. (B): Profile of 44 genes that are not differentially expressed in L-MSCs compared to N-MSC samples. The relative expression of each gene was normalized to a computed endogenous control (aggregated median of the B2M and EIF2B1 expression values). Bars represent medians and error bars semi-interquartile ranges.

FIG. S4. Both L-MSCs and N-MSCs promote quiescence of leukemic cells mainly by direct contact. Leukemic cells (CD45 $5^{\text {pos }}$ cell fraction) were analyzed by flow cytometry. (A, B, C, D): Cell cycle analysis of KGla $(\mathrm{A}, \mathrm{C})$ and primary blast $(\mathrm{B}, \mathrm{D})$ cells after 7-AAD/Ki-67 staining. Percentages of MSC-free leukemic cells in the different phases of the cell cycle are shown (medians and semi-interquartile ranges) (A and B). Representative images of cell cycle distribution analysis of leukemic cells co-cultured or not with MSCs (C and D). 


\section{Figure S1}

A

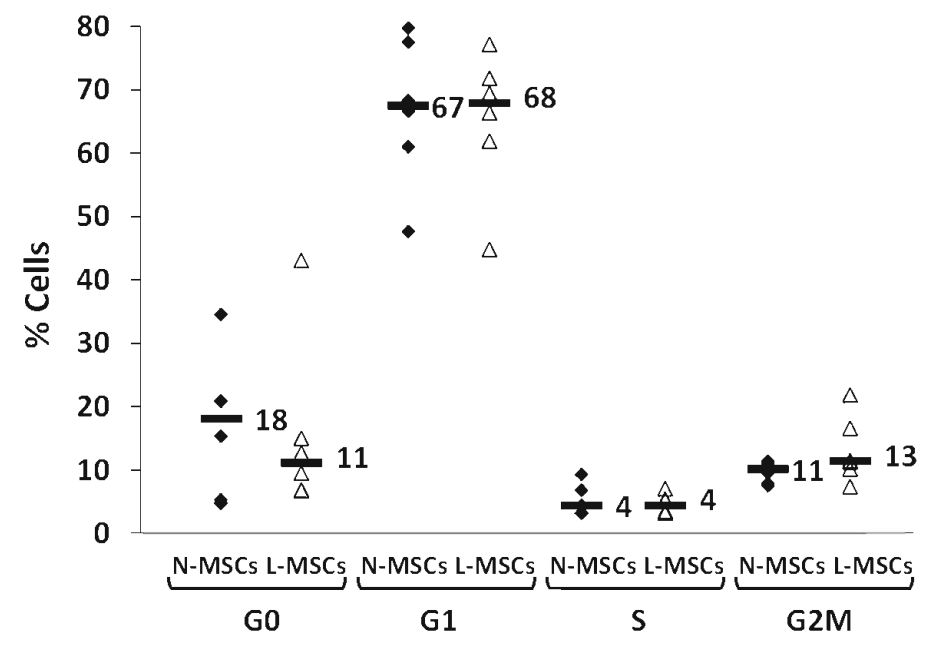

- N-MSCs

$\triangle$ AML-MO/1 MSCs

- Median

B
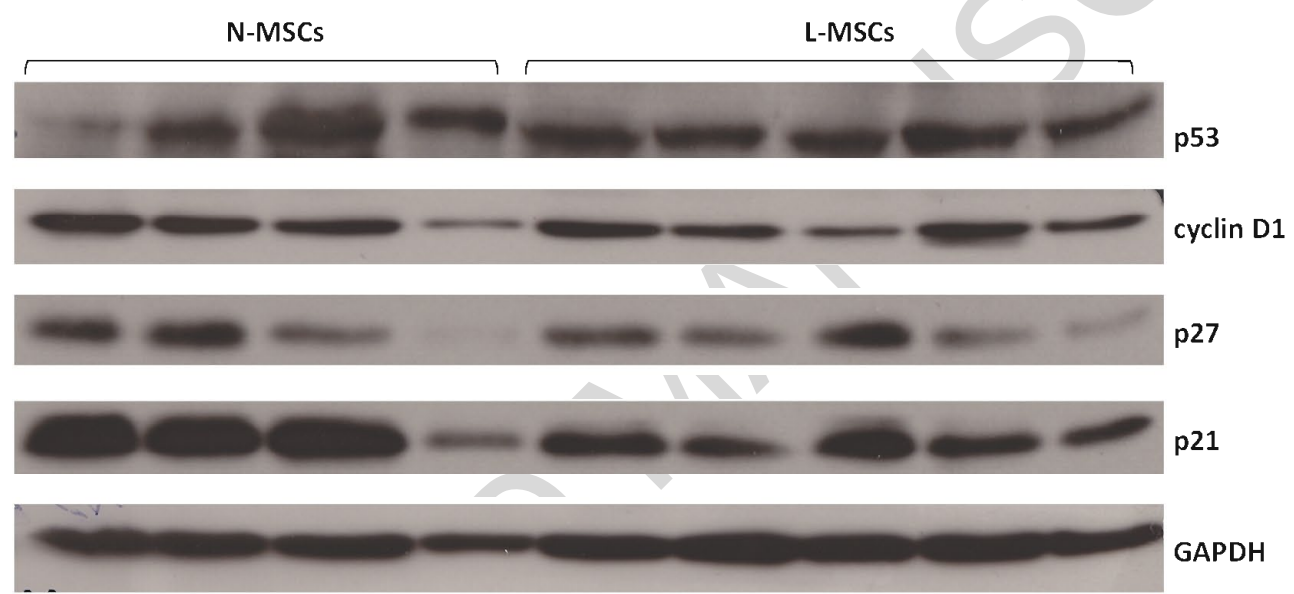

C

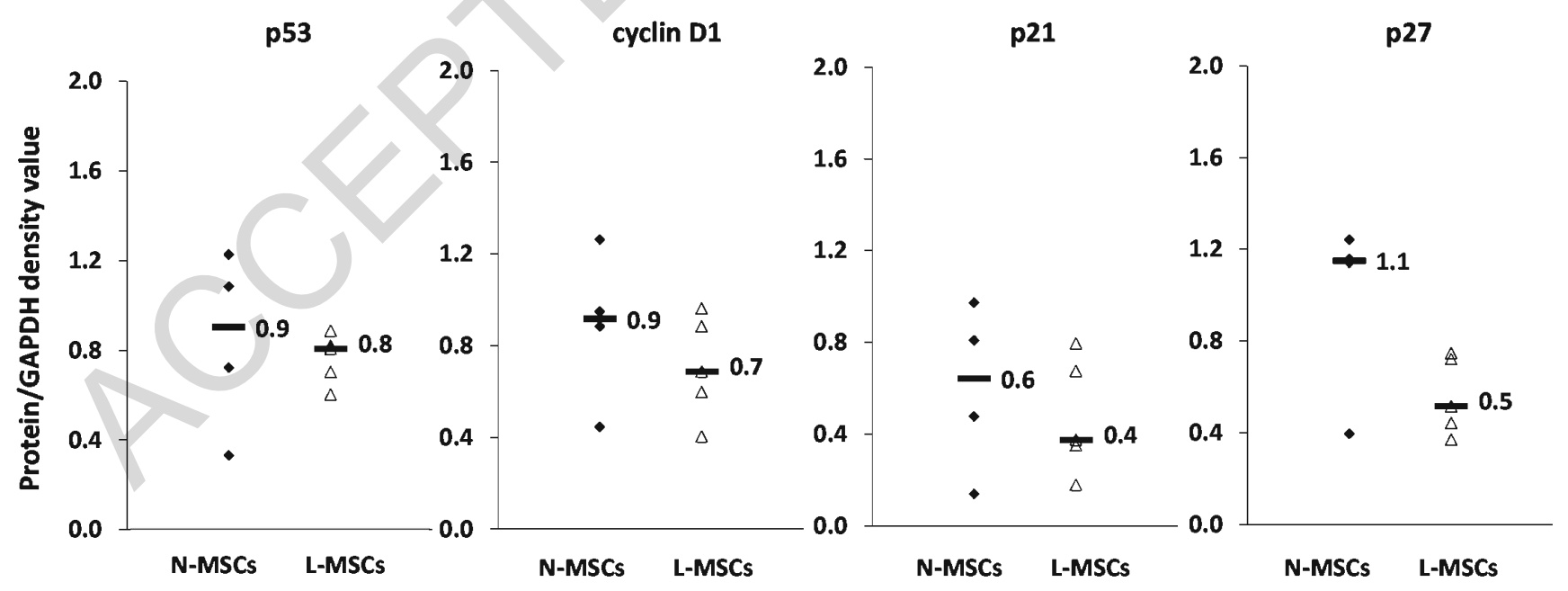


Figure S2

A

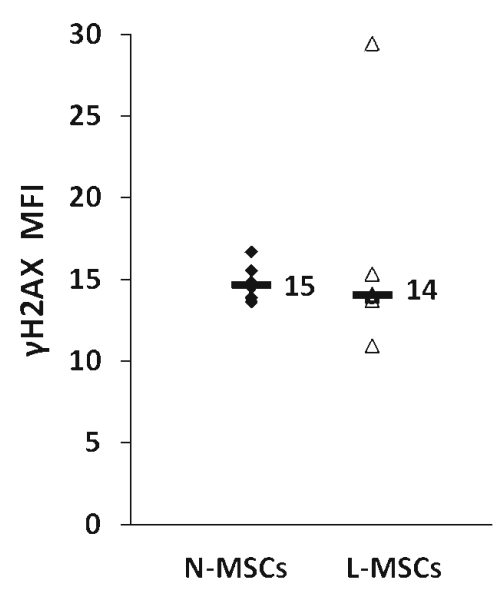

C

$$
\begin{array}{r}
10 \mathrm{~kb}= \\
8 \mathrm{~kb}= \\
6 \mathrm{~kb}-
\end{array}
$$

L-MSCS

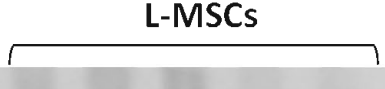

B

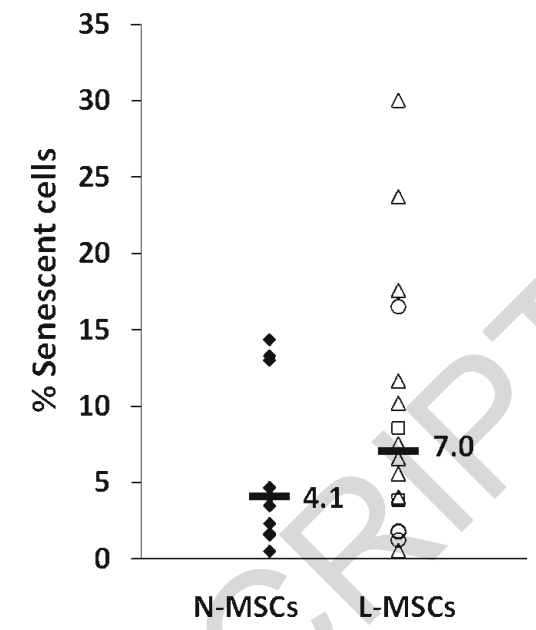

D

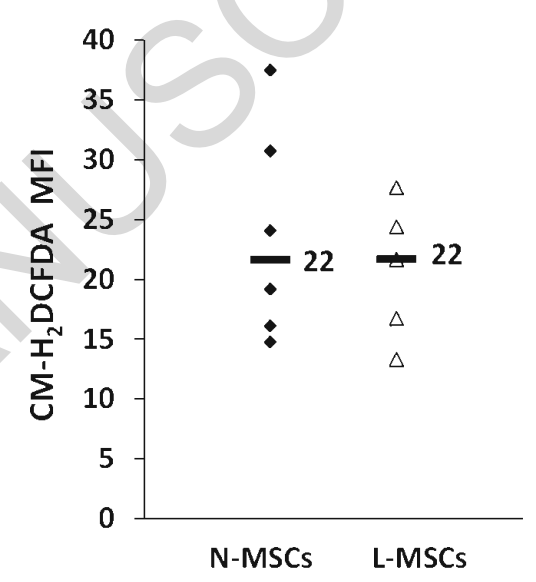




\section{Figure S3}

A

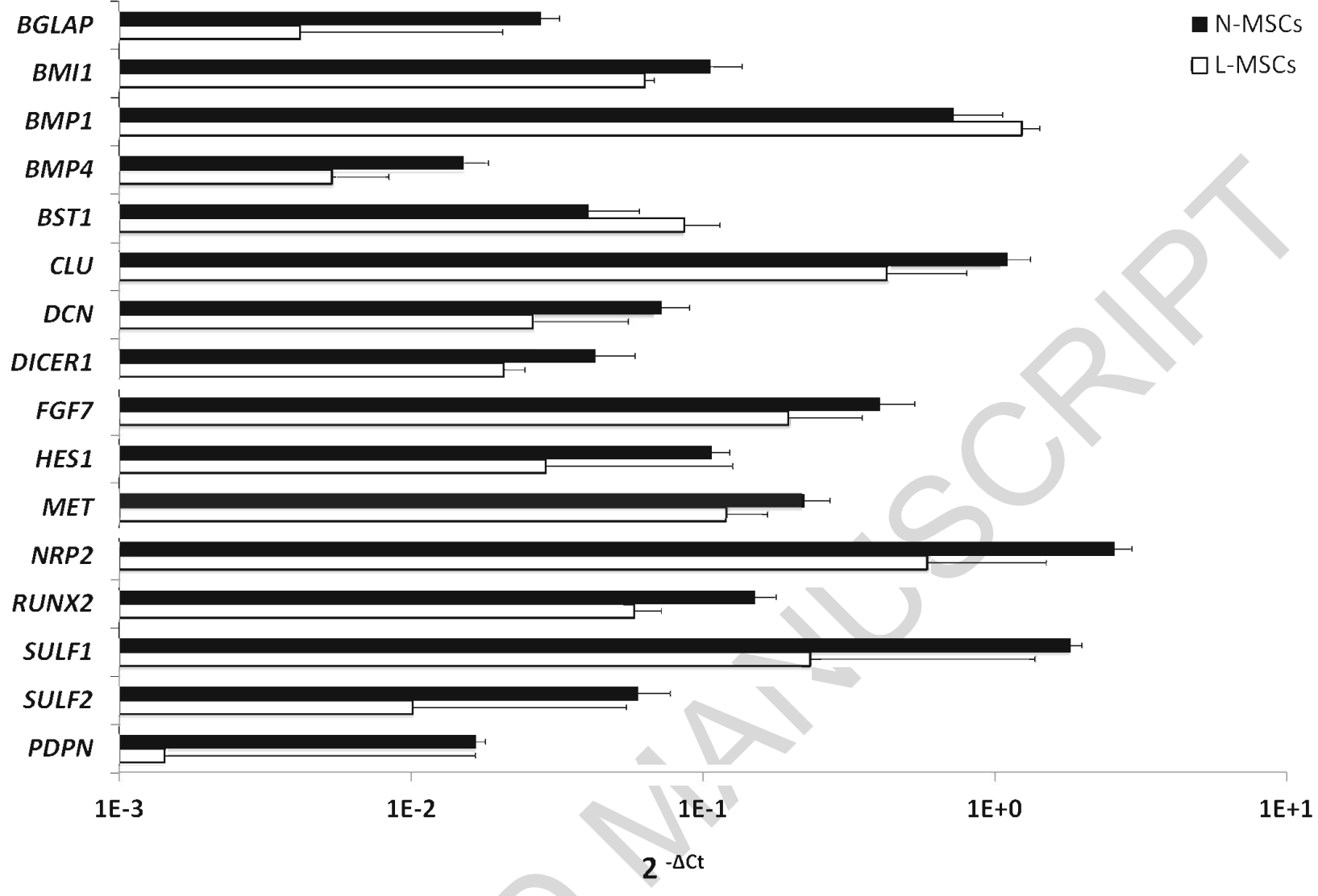




\section{Figure S3}

B

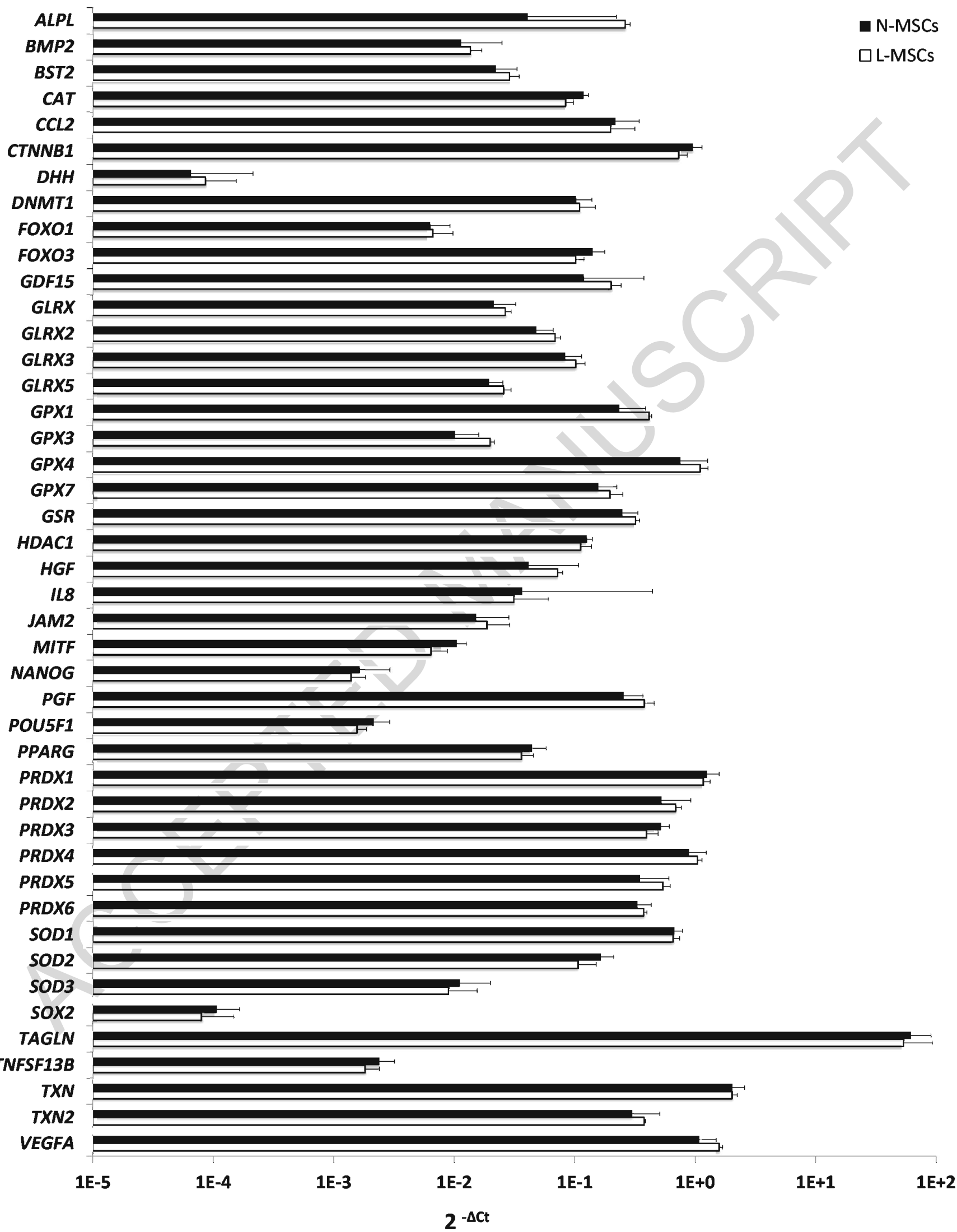


Figure S4

A

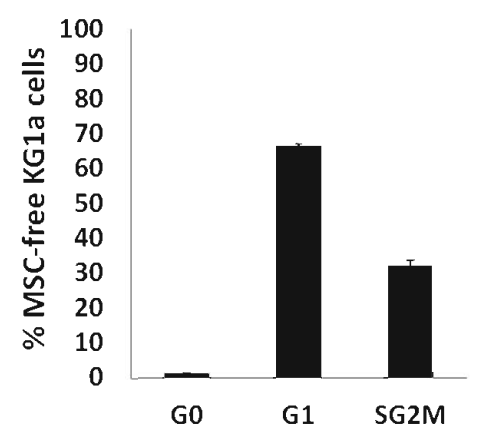

B

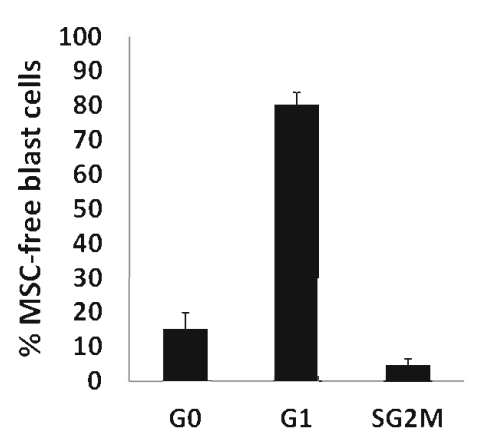

C

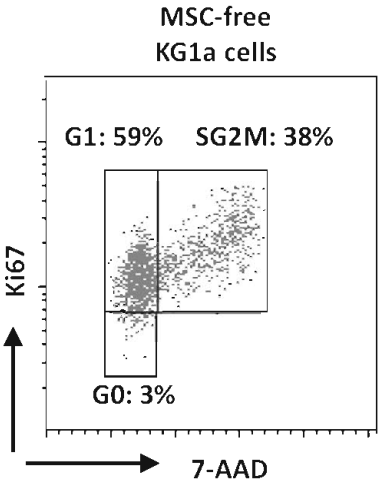

D

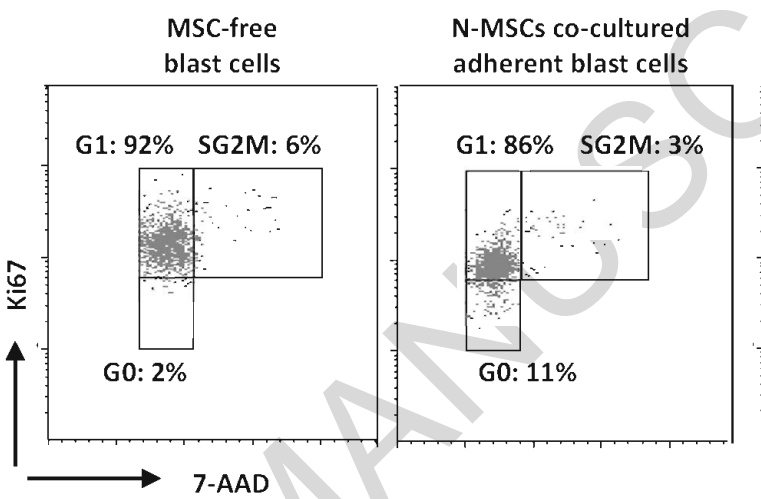

L-MSCs co-cultured adherent KG1a cells

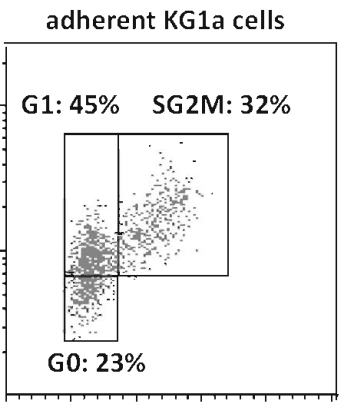

\section{G1: $48 \%$ SG2M: $36 \%$}

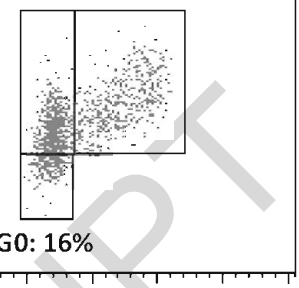

L-MSCs co-cultured adherent blast cells

G1: $87 \%$ SG2M: $3 \%$

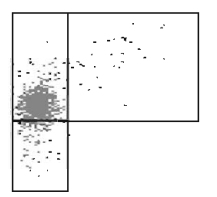

G0: $10 \%$ 